\author{
RESEARCH ARTICLE \\ 10.1029/2018JC014836 \\ Key Points: \\ - The Antilles Current carries 4.7 Sv \\ northward at $26.5^{\circ} \mathrm{N}$ in the time \\ mean during 2005-2015, with a daily \\ standard deviation of $7.5 \mathrm{~Sv}$ \\ - The dominant time scales of \\ variability for the flow are near 70 \\ and 180 days, with little indication of \\ a meaningful seasonal cycle \\ - Geostrophic and direct velocity \\ estimates within the Antilles \\ Current core differ, with the direct \\ estimates being noticeably weaker
}

Correspondence to:

C. S. Meinen,

christopher.meinen@noaa.gov

Citation:

Meinen, C. S., Johns, W. E., Moat, B. I., Smith, R. H., Johns, E. M., Rayner, D., et al. (2019). Structure and variability of the Antilles Current at $26.5^{\circ} \mathrm{N}$. Journal of Geophysical Research: Oceans, 124. https://doi.org/10.1029/2018JC014836

Received 4 DEC 2018

Accepted 8 MAY 2019

Accepted article online 10 MAY 2019

Published 2019. This article is a U.S. Government work and is in the public domain in the USA.

\section{Structure and Variability of the Antilles Current at $26.5^{\circ} \mathrm{N}$}

\author{
Christopher S. Meinen' (D), William E. Johns², Ben I. Moat ${ }^{3}$ (D), Ryan H. Smith' ${ }^{1}$, \\ Elizabeth M. Johns ${ }^{1}$, Darren Rayner ${ }^{3}$ (D), Eleanor Frajka-Williams ${ }^{3}$ (D), Rigoberto F. Garcia ${ }^{1,4}$, \\ and Silvia L. Garzoli ${ }^{1,4}$ \\ ${ }^{1}$ NOAA/Atlantic Oceanographic and Meteorological Laboratory, Miami, FL, USA, ${ }^{2}$ Rosenstiel School of Marine and \\ Atmospheric Science, University of Miami, Miami, FL, USA, ${ }^{3}$ National Oceanography Centre, Southampton, UK, \\ ${ }^{4}$ Cooperative Institute for Marine and Atmospheric Studies, University of Miami, Miami, FL, USA
}

Abstract Observations from five different systems provide a robust picture of the structure and variability of the Antilles Current, an important contributor to the oceanic flux budget, at $26.5^{\circ} \mathrm{N}$ during 2005-2015. The analysis includes three direct measurement technologies (current meters, shipboard acoustic Doppler current profilers, and lowered acoustic Doppler current profilers) and two geostrophy-based measurement technologies (conductivity-temperature-depth profilers and pressure-equipped inverted echo sounders). The direct systems are shown to produce weaker, and less variable, Antilles Current transport estimates than the geostrophy-based systems. The record-length-mean geostrophic estimate for the Antilles Current is 4.7 Sverdrups (Sv; $1 \mathrm{~Sv}=10^{6} \mathrm{~m}^{3} / \mathrm{s}$ ), and the daily temporal standard deviation is $7.5 \mathrm{~Sv}$. The variations of the Antilles Current transport exceed those of the entire basin-wide meridional overturning circulation, illustrating the impact of this unusual current. Seasonal variability shows a maximum northward transport in August-September; however, the seasonal component of the variability is weak, and aliasing of higher frequencies is still a problem even with 10.5 years of data. The dominant time scales of variability in the spectra are at 70 and 180 days, and there is indication of westward propagation of Rossby Wave-like features into the region at a speed of $9 \mathrm{~cm} / \mathrm{s}$. There is no significant correlation between the Antilles Current transport variations and those of the Florida Current at $27^{\circ} \mathrm{N}$, in phase or at lags/leads of up to 5 years, likely reflecting the varying coastal wave/wall jet time scales for information to pass from the basin interior through the Bahamas Islands.

Plain Language Summary The Antilles Current carries waters northward and northwestward around the Bahamas Islands. While scientists have known that the Antilles Current existed for decades, it has not been studied nearly as much as the stronger Florida Current to the west, even though studies have suggested that the Antilles Current plays a significant role in the north-south exchange of heat and salt within the North Atlantic. This study uses five different types of measurement systems to quantify how much water is being carried by the Antilles Current every day, how variable that flow is over a 10.5 -year time period, and what typical salinity, temperature, and dissolved oxygen contents are for the waters carried by the flow. The study finds that on average, this current is carrying $4.7 \times 10^{6} \mathrm{~m}^{3}$ of water per second northward and that this flow can vary by more than $100 \%$ from day to day (i.e., some days the flow can actually reverse and go southward). The study reveals the time scales on which the current tends to vary, and it also provides some tantalizing evidence that the physics of the current may not be as simple as has been previously thought.

\section{Introduction}

The Antilles Current is a western boundary current that flows northward and then northwestward along and around the northern Bahamas islands in the subtropical North Atlantic before joining the Gulf Stream (e.g., Tomczak \& Godfrey, 1994). It is unusual in that it is neither surface intensified like the Gulf Stream nor bottom intensified like the Deep Western Boundary Current (DWBC). While knowledge of the existence of the Gulf Stream dates back at least to the seventeenth and eighteenth centuries, it was not until the late nineteenth century that mariners began to have consistent observations that there was a smaller current flowing northward or northwestward offshore of the Bahamas Islands to join the Gulf Stream further north (e.g., Findlay \& Maury, 1853; Pillsbury, 1889, 1890). Direct measurements of the current and the commonplace use of the name "Antilles Current," followed by the middle of the twentieth century (e.g., Costin, 1968; Maloney, 1968; Wüst, 1924), although as the late twentieth century approached, there was still 
disagreement about whether the Antilles Current existed as a consistent flow (e.g., Duncan et al., 1982; Gunn \& Watts, 1982).

By the end of the twentieth century and the start of the 21st century, more extensive direct and indirect velocity observations have demonstrated that the Antilles Current clearly does exist in a time-mean sense east of Abaco Island in the northern Bahamas Islands, although estimates of the mean volume transport vary significantly between 1 and 6 Sv (e.g., Frajka-Williams et al., 2013; Johns et al., 2008; Lee et al., 1990, 1996; Meinen et al., 2004). The current has a peak velocity at roughly 400-m depth with velocities exceeding 30 $\mathrm{cm} / \mathrm{s}$, and the velocity drops away toward zero both near the sea surface and at roughly 1,000-m depth (e.g., Hacker et al., 1996; Johns et al., 1997; Leaman \& Harris, 1990; Rosenfeld et al., 1989). While the general consensus is that the waters carried within the Antilles Current are primarily recirculating through/within the Gulf Stream and the subtropical gyre (e.g., Schmitz \& McCartney, 1993), some analyses have suggested that the Antilles Current may also be carrying a portion of the warm upper limb of the meridional overturning circulation-and hence, it has importance to the basin-wide meridional heat and salt transports (e.g., Frajka-Williams et al., 2013). Studies using observations from different time periods have differed as to whether or not they found that the variability of the Antilles Current transport was correlated with variations in the Florida Current as they both flow northward to feed the Gulf Stream (e.g., Frajka-Williams et al., 2013; Meinen et al., 2004).

Despite the many aforementioned studies (and more cited within them), the basic structure, variability, and dynamics of the Antilles Current are still not well understood. The introduction of long-term overlapping arrays of moorings extending roughly $500-\mathrm{km}$ offshore of the Bahamas Islands along $26.5^{\circ} \mathrm{N}$ since 2004 (e.g., Cunningham et al., 2007; Frajka-Williams et al., 2016; Kanzow et al., 2007; McCarthy et al., 2015; Meinen et al., 2006; Meinen et al., 2013; Rayner et al., 2011; Smeed et al., 2018), coupled with many repeated hydrographic sections collected along the arrays (e.g., van Sebille et al., 2011), has produced an excellent data set for a detailed study of the Antilles Current. A few years of data from this array have been used to study the Antilles Current previously (Frajka-Williams et al., 2013; Johns et al., 2008); however, more than 10 years of continuous daily data now exist, so both longer time scales and more robust statistics at all time scales are available from this now much longer record. Furthermore, the quantity of high quality hydrographic data available from repeated research cruises along the array provides an unprecedented data set for analyzing the water properties of the flows in the region. Together, these outstanding data sets will allow for the most accurate analysis of the Antilles Current available to date. This paper will focus on an analysis of the time period from 8 May 2005 through 23 November 2015.

\section{Data and Methods}

The analyses presented herein utilize data from several different well-known measurement systems. For the sake of brevity, only important differences in the applications of these systems to this study will be presented in detail here, with other details left to the cited references.

An observational suite of moored instruments along $26.5^{\circ} \mathrm{N}$ east of Abaco Island, Bahamas, has been in operation since 2004. The array involves seven tall moorings (each equipped with a mix/subset of single point acoustic current meters, integrated temperature-salinity-pressure sensors, and upward looking Acoustic Doppler Current Profilers [ADCPs]), six Pressure-equipped Inverted Echo Sounders (PIESs), four or five Bottom Pressure Recorders (BPRs), and one short ADCP mooring up on the continental shelf (Figure 1). Table 1 presents the nominal locations and types of the moored instruments. These instruments have been/are supported through funding from the Natural Environment Research Council in the United Kingdom (for the RAPID AMOC project), from the National Science Foundation in the United States (for the Meridional Overturning Circulation Heat-flux Array project), and from the National Oceanic and Atmospheric Administration also in the United States (for the Western Boundary Time Series project). All three funding agencies have also supported hydrographic observations collected along the mooring line during research cruises. During the period encompassed by this study, 15 research cruises collected detailed Conductivity-Temperature-Depth-Dissolved Oxygen $\left(\right.$ CTD- $\left.\mathrm{O}_{2}\right)$ sections along the mooring line (Table 2). Most of the cruises also collected Shipboard ADCP (SADCP) and Lowered ADCP (LADCP) data. The May 2005 cruise collected two complete sections along the line separated in time by 10 days, so there are a total of 16 sections of data available in the time period studied herein. 

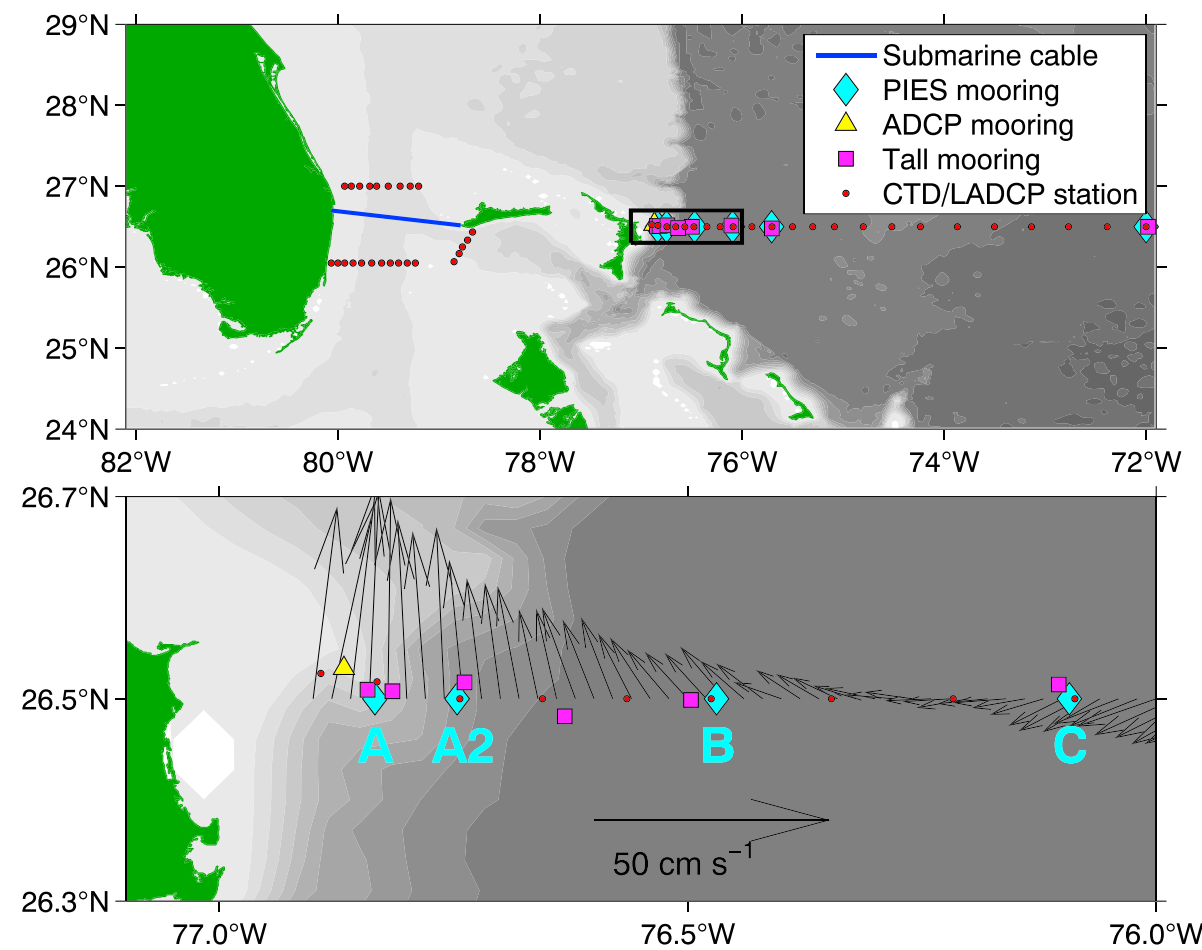

Figure 1. Map of the study region showing the locations of the moored instruments and the locations of the regular CTD/ LADCP casts. Mooring types are shown in the legend. Lower panel presents the details of the region highlighted by the black box in the top panel; the PIES sites shown in this panel (light blue diamonds) are named with bold light blue letters. Black vectors denote the average 405-m velocities from the Shipboard ADCP sections discussed in the text; scale vector shown at bottom center of lower panel. Solid green indicates land, while the gray shading shows the bottom topography from the Smith and Sandwell (1997) data set using a 500-m contour interval. PIES = Pressure-equipped Inverted Echo Sounders; ADCP = Acoustic Doppler Current Profiler; CTD = Conductivity-Temperature-Depth; LADCP $=$ Lowered ADCP.

The tall moorings involved in the array have typically been deployed for periods of 12 to 18 months at a time; the deployment periods for the short ADCP mooring up on the continental shelf have been the same. The PIES moorings have typically been deployed for a period of roughly 4 years, with the data downloaded

Table 1

Locations of the Instruments

\begin{tabular}{|c|c|c|c|c|}
\hline Site name & Mooring type & Nominal latitude & Nominal longitude & Notes \\
\hline Site A & PIES & $26.52^{\circ} \mathrm{N}$ & $76.83^{\circ} \mathrm{W}$ & Site was added May 2005 \\
\hline Site A2 & PIES & $26.50^{\circ} \mathrm{N}$ & $76.75^{\circ} \mathrm{W}$ & Site was added April 2010 \\
\hline Site B & PIES & $26.49^{\circ} \mathrm{N}$ & $76.47^{\circ} \mathrm{W}$ & \\
\hline Site C & PIES & $26.50^{\circ} \mathrm{N}$ & $76.09^{\circ} \mathrm{W}$ & \\
\hline Site D & PIES & $26.50^{\circ} \mathrm{N}$ & $75.71^{\circ} \mathrm{W}$ & \\
\hline Site E & PIES & $26.50^{\circ} \mathrm{N}$ & $72.00^{\circ} \mathrm{W}$ & \\
\hline WB-ADCP & $\mathrm{ADCP}$ mooring & $26.53^{\circ} \mathrm{N}$ & $76.87^{\circ} \mathrm{W}$ & \\
\hline WB-0 & CM mooring & $26.51^{\circ} \mathrm{N}$ & $76.84^{\circ} \mathrm{W}$ & \\
\hline WB-1 & $\mathrm{CM} / \mathrm{DH}$ mooring & $26.51^{\circ} \mathrm{N}$ & $76.82^{\circ} \mathrm{W}$ & \\
\hline WB-2 & $\mathrm{CM} / \mathrm{DH}$ mooring & $26.52^{\circ} \mathrm{N}$ & $76.74^{\circ} \mathrm{W}$ & \\
\hline WB-H2 & $\mathrm{CM} / \mathrm{DH}$ mooring & $26.48^{\circ} \mathrm{N}$ & $76.63^{\circ} \mathrm{W}$ & Site was added in April 2008; only has sensors below 1,200 m \\
\hline WB-3 & $\mathrm{CM} / \mathrm{DH}$ mooring & $26.50^{\circ} \mathrm{N}$ & $76.50^{\circ} \mathrm{W}$ & \\
\hline WB-C & CM mooring & $26.51^{\circ} \mathrm{N}$ & $76.10^{\circ} \mathrm{W}$ & Site was added in March 2014 \\
\hline WB-4 & $\mathrm{CM} / \mathrm{DH}$ mooring & $26.48^{\circ} \mathrm{N}$ & $75.70^{\circ} \mathrm{W}$ & Site was moved from $76.04^{\circ} \mathrm{W}$ in April 2009 \\
\hline WB-5 & DH mooring & $26.50^{\circ} \mathrm{N}$ & $71.98^{\circ} \mathrm{W}$ & Site was discontinued in March 2014 \\
\hline
\end{tabular}

Note. Mooring types refer to pressure-equipped inverted echo sounder (PIES); Acoustic Doppler Current Profiler (ADCP); Current Meter (CM; multiple sensors at different depths); Dynamic Height (DH; which utilizes temperature, salinity, and pressure sensors at multiple depths). Note that for most deployments, a Bottom Pressure Recorder was deployed near the base of each of the following tall moorings: WB-2, WB-3, WB-4, and WB-5. 
Table 2

Ship Sections Used in This Study; Sections Were Required to Have Both Conductivity-Temperature-Depth and LADCP Data for Inclusion

\begin{tabular}{lllll}
\hline Cruise dates & \multicolumn{1}{c}{ Dates of section } & \multicolumn{1}{c}{ Vessel } & \multicolumn{1}{c}{ SADCP type } \\
\hline 2-26 May 2005 & 4-8 May \& 18-23 May & RV Knorr & OS75kHz \& NB150kHz & BB150kHz \& WH300kHz \\
11-24 Sep. 2005 & 14-21 Sep. & NOAA Ship Ronald H. Brown & OS75kHz & BB150kHz \& WH300kHz \\
9-28 Mar. 2006 & 13-19 Mar. & NOAA Ship Ronald H. Brown & OS75kHz & Multiple configurations \\
25 Sep. to 12 Oct. 2006 & 28 Sep to 2 Oct. & RV Seward Johnson & OS38kHz \& OS150kHz & BB150kHz \& WH300kHz \\
21 Mar. to 10 Apr. 2007 & 31 Mar. to 6 Apr. & NOAA Ship Ronald H. Brown & OS75kHz & BB150kHz \& WH300kHz \\
11-21 Sep. 2007 & 13-18 Sep. & NOAA Ship Ronald H. Brown & OS75kHz & BB150kHz \& WH300kHz \\
4-30 Apr. 2008 & 8-13 Apr. & RV Seward Johnson & OS38kHz \& OS150kHz & Multiple configurations \\
16 Apr. to 5 May 2009 & 18-24 Apr. & NOAA Ship Ronald H. Brown & OS75kHz & Multiple configurations \\
13 Apr. to 3 May 2011 & 15-20 Apr. & RV Knorr & OS75kHz \& WH150kHz & WH150kHz \& WH300kHz \\
15 Feb. to 5 Mar. 2012 & 18-24 Feb. & NOAA Ship Ronald H. Brown & OS75kHz & WH150kHz \& WH300kHz \\
24 Sep. to 10 Oct. 2012 & 26 Sep. to 1 Oct. & RV Endeavor & OS75kHz \& WH150kHz & WH150kHz \& WH300kHz \\
19 Feb. to 5 Mar 2013 & 21-27 Feb. & NOAA Ship Ronald H. Brown & OS75kHz & WH150kHz \& WH300kHz \\
15-31 Mar. 2014 & 16-22 Mar. & RV Atlantic Explorer & OS75kHz & OS75kHz \& WH150kHz \\
14-27 Feb. 2015 & 16-23 Feb. & RV Endeavor & WH150kHz & WH150kHz \& WH300kHz \\
3-19 Oct. 2015 & 5-11 Oct. & RV Endeavor & WH150kHz \& WH300kHz \\
\hline
\end{tabular}

Note. For the Acoustic Doppler Current Profiler (ADCP) types, the following abbreviations are used: OS = Ocean Surveyor; NB = Narrow Band; BB = Broad Band; and WH = Work Horse; the down-looking Lowered ADCP (LADCP) instrument is listed first in the final column. Note that the following sections had insufficient data for use in the Shipboard ADCP (SADCP) averaging: April 2008, September 2012, and October 2015. Note also that two complete sections along the mooring line were completed during the May 2005 cruise.

acoustically every 6 to 9 months during the research cruises. The BPR have typically been deployed for periods of 18-24 months at a time. Research cruises were conducted to turn around the moorings and collect CTD- $\mathrm{O}_{2} / \mathrm{LADCP} / \mathrm{SADCP}$ data nominally every 6 months during the early part of the array (before 2013) and every 9 months in the later years.

\subsection{Current Meter Processing}

The tall moorings typically include up to eight current meters on each mooring between 100-m depth and the bottom, and select moorings also include an upward-looking ADCP at a nominal 150-m depth to capture velocities closer to the surface (e.g., Johns et al., 2008). The single point acoustic current meters on the moorings collect data hourly, and they are subsequently smoothed with a fourth-order Butterworth filter with a 40-hr cutoff period. The filter is passed both forward and backward to avoid phase shifting. After filtering, the currents are typically subsampled to one value every $12 \mathrm{hr}$. The velocity profiles collected by the ADCP instruments on the moorings, typically located near the top of the mooring pointed upward toward the surface, are processed in a similar manner. The measured zonal and meridional velocities, both from the single point current meters and the moored ADCP, are interpolated using Akima splines onto a regular grid in depth (resolution $20 \mathrm{~m}$ ) and are interpolated linearly onto a regular grid of offshore distance (resolution $500 \mathrm{~m}$ ). Mooring motion (i.e., mooring blow-down) is taken into account during the gridding by utilizing the pressure measurements of collocated sensors on the moorings (see below). The details of the processing of the current meters and the ADCP follow the methods presented in W. E. Johns et al. (2008).

\subsection{Moored Temperature-Salinity-Pressure Sensor Processing}

The tall moorings include one or more Seabird SBE37 MicroCAT sensor packages, each of which collects measurements of temperature, salinity, and pressure every 15, 30, or $60 \mathrm{~min}$, depending on the deployment. The MicroCAT sensors are initially calibrated by the manufacturer, and long-term sensor drift is evaluated through calibration at sea against recently calibrated CTD sensors during deep concurrent casts. The fullresolution observations are smoothed with a sixth-order Butterworth low-pass filter with a 48-hr cutoff period; again, the filter is passed both forward and back to avoid phase shifting. The resulting smoothed records are subsampled to one value per $12 \mathrm{hr}$. The observations are vertically interpolated onto a regular 20-dbar vertical grid using a seasonally varying hydrography-derived canonical profile following the method of W. E. Johns et al. (2005), taking into account the mooring motion through analysis of the pressure sensor data. The details of the processing of the MicroCAT data are presented in McCarthy et al. (2015). 
For this study, the gridded temperature and salinity profiles produced from the tall moorings are primarily used to simulate the travel time that would be measured at 1,000 dbar (e.g., Meinen \& Watts, 1998). Travel time is simulated by vertically integrating the sound speed profiles calculated from the gridded mooring profiles (e.g., Meinen \& Watts, 1997). These simulated travel time values are used to fill gaps in time when the PIES moorings experienced failures (see Appendix A for more detail).

\subsection{BPR Processing}

A BPR was deployed near the base of tall moorings WB-1, WB-2, WB-3, WB-4, and WB-5 on an independent rigid small mooring ("lander") for roughly 2-year deployments throughout the study period. For some of the deployments, two BPR landers were deployed at each site, on schedules shifted by 1 year, in order to better quantify the sensor drift in the pressure gauges. The hourly pressure observations have the strong tidal signals removed via harmonic analysis, and the resulting records are then further smoothed with a Tukey lowpass filter with a 2.1-day cutoff period. The details of the BPR processing can be found in McCarthy et al. (2015).

For the present study, the BPR records are used to fill the time gaps in the PIES pressure records when the latter suffered equipment failures. See Appendix A for more details.

\subsection{PIES Processing}

The PIES is a small self-contained moored instrument that makes 2-hourly measurements: the bottom pressure and the total time for a $12-\mathrm{kHz}$ acoustic pulse to travel up from the bottom-moored instrument to the sea surface, reflect, and return to the PIES. The bottom pressure measurements made by the PIES are very similar to those of the BPR. For the PIES, the exponential-linear drifts are removed via standard methods (e.g., Watts \& Kontoyiannis, 1997; Donohue et al., 2010), and the tidal signals are removed from the hourly bottom pressure records using a Response Analysis technique (e.g., Munk \& Cartwright, 1966). The pressure records are further smoothed with a second-order Butterworth filter with a 72-hr cutoff period, with the filter passed both forward and back to avoid phase shifting. The resulting smoothed records are subsampled to one value per day at noon UTC.

The hourly PIES travel time measurements are also first smoothed with a second-order Butterworth filter with a 72-hr cutoff period, with the filter passed both forward and back to avoid phase shifting. These travel time values are then also subsampled to one value per day at noon UTC. These daily travel time values are then calibrated into the equivalent travel time values that would have been measured at 1,000 dbar through the use of concurrent CTD observations during the deployment, recovery, and intervening research cruises (e.g., Meinen \& Watts, 1998). Note that while the travel time signal calibrated to 1,000 dbar is influenced by temperature and salinity variations throughout the full water column, because the travel time measured by the PIES captures variations at all depths, the impact of signals at depths below $1,000-1,500 \mathrm{dbar}$ are much smaller simply because the temperature and salinity variations at great depth are an order of magnitude smaller than those observed in the upper water column (e.g., Meinen et al., 2004). The "errors" induced in the travel time calibration to 1,000 dbar by deep temperature and salinity variations are included in the error bars derived for the Antilles Current (see Appendix B).

The "calibrated" travel time is then traditionally analyzed via the "Gravest Empirical Mode" (GEM) technique, wherein hydrographic data from the region are used to create two-dimensional look-up tables of temperature, salinity, and density (Meinen \& Watts, 2000). These GEM look-up tables are combined with the daily travel time records from each PIES to produce daily full-water-column profiles of temperature, salinity, and density at each PIES site. Meinen et al. (2004) first applied the GEM method to pressure and travel time data in the Antilles Current and adjacent DWBC, and Meinen and Luther (2016), and citations therein, have demonstrated that the PIES-GEM method is capable of capturing uncorrelated velocity variability at different depths. In particular, Meinen et al. $(2004,2006,2013)$ provide detailed examples of the GEM application to PIES along the $26.5^{\circ} \mathrm{N}$ section. Meinen et al. (2004) presents an example GEM field for the region (Figure 2 in that paper), and the appendix of that paper presents an error analysis for estimates of the flow for both the Antilles Current and the DWBC. The application of the GEM method for the present study is similar to previous studies, with two differences. First, the GEM fields were updated using both CTD and Argo profile data that has been collected over the past 10 years since the GEM fields were last updated. Second, typically a single set of GEM fields is applied to all of the PIES within a geographically contained array (i.e., previous 
studies in this region have applied the same set of GEM fields to all of the PIES from sites A to E; see Table 1). A careful look in this study, however, found that the application of the GEM method to the PIES within the uncommonly structured Antilles Current would be better if a separate set of GEM fields was created for the shallower PIES at site A using the 431 hydrographic casts (CTD and Argo) available west of $76.2^{\circ} \mathrm{W}$ between $25^{\circ} \mathrm{N}$ and $28^{\circ} \mathrm{N}$ and another set for the deeper PIES from site B offshore using the 2,034 hydrographic casts east of $76.75^{\circ} \mathrm{W}$ between $25^{\circ} \mathrm{N}$ and $28^{\circ} \mathrm{N}$. To reduce discontinuities at the interface, the GEM fields for the shallow and deep regions were averaged to create a third set that was applied to the data from site A2. The scatter around these GEM fields, essentially error bars for the estimated temperature, salinity, and density values, is similar to that observed earlier (e.g., Figure 2 of Meinen et al., 2004); the results of this modified technique demonstrated the best comparisons with the other data sets collected along the array (as will be shown shortly).

The resulting daily full-water-column profiles of density at each PIES site can be vertically integrated to yield daily profiles of dynamic height anomalies, and dynamic height anomaly profiles from neighboring sites can be differenced to yield daily profiles of the geostrophic meridional velocity relative to an assumed level of no motion via the standard geostrophic method (e.g., Gill, 1982). Differencing the bottom pressure from neighboring sites gives an absolute velocity reference; only the time-varying component can be derived from the bottom pressure difference, while the time mean must be derived from either a numerical model or an alternative data set. For any of these methods of including a time-mean reference velocity, the combined reference velocity is then added to the relative velocity profiles to yield absolute geostrophic velocity profiles (e.g., Meinen \& Watts, 2000). The one difference in this study is that for the span between sites A and A2 and the span between sites A2 and B, instead of using the bottom pressure differences over the steeply sloping bottom for the absolute velocity reference, the gridded current meter velocities at 1,000 dbar were integrated between the pairs of sites (e.g., between sites A and A2), and these integrated velocities were used to provide the reference for the PIES-GEM based relative velocity profiles. The resulting "hybrid" velocity profiles within these two spans thus depend on the PIES-GEM data for the baroclinic structure of the flow relative to 1,000 dbar and on the current meter gridded velocity at 1,000 dbar.

\subsection{CTD- $\mathrm{O}_{2}$ Processing}

CTD-O ${ }_{2}$ sections have been collected semiroutinely along $26.5^{\circ} \mathrm{N}$ since 1986 (e.g., Fine \& Molinari, 1988; Molinari et al., 1992, 1998; van Sebille et al., 2011), and since the turn of the millennium, the station locations occupied on each cruise have been mostly the same 28 stations along $26.5^{\circ} \mathrm{N}$ between the $500-\mathrm{m}$ isobath just offshore of Abaco Island, the Bahamas, and $69.5^{\circ} \mathrm{W}$ (Figure 1). Fifteen cruises occurred during the 2005-2015 time period discussed herein, and during the first cruise, two sections were collected along the line, so 16 total CTD- $\mathrm{O}_{2}$ sections are available for this analysis (Table 2). In all cases, these CTD-O data were collected using a Sea-bird SBE911plus system configured with dual conductivity, temperature, and dissolved oxygen sensors and processed via standard methods (e.g., Hooper \& Baringer, 2016). Averages and standard deviations of the properties were calculated station-by-station, as the same station locations are used on each survey. Geostrophic velocities calculated with the CTD data were determined relative to an assumed level of no motion at the ocean surface; no absolute reference velocity was applied to the CTDderived relative velocities presented herein to allow the CTD-derived velocities to be truly independent of the other data sets to which they are compared.

\subsection{LADCP Processing}

Full ocean depth LADCP data were collected using Teledyne RD Instruments ADCPs mounted on the CTD frame. Typically, a dual-LADCP system was employed configured with a $150-\mathrm{kHz}$ downward-facing instrument in tandem with a $300-\mathrm{kHz}$ upward-facing instrument (on a small number of stations, only singleLADCP data are available). The LADCP data presented herein were all processed using version 10 of the GEOMAR Visbeck software, which incorporates both CTD and SADCP data when available to improve LADCP data quality (Visbeck, 2002). The details of the types of LADCP used during each cruise are presented in Table 2. Averages and standard deviations of the LADCP velocities were calculated station by station as the same station locations are used on each survey. 


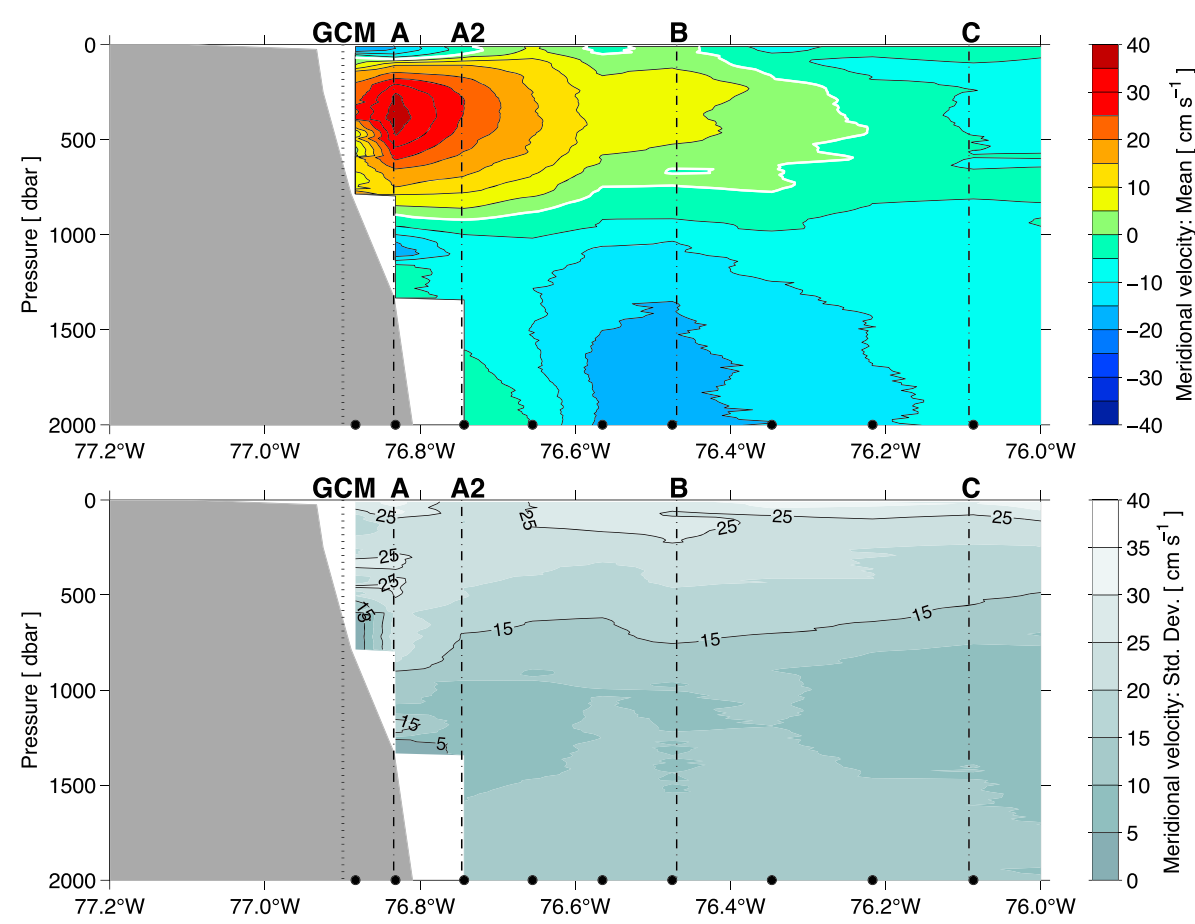

Figure 2. Average (top) and standard deviation (bottom) meridional velocity from 16 Lowered Acoustic Doppler Current Profiler sections collected between 2005 and 2015. Positive values indicate northward flow; the zero contours are indicated by the bold white lines. Lowered Acoustic Doppler Current Profiler profiles were collected at the same nominal locations (black dots along lower axis) during each cruise section. Gray shading indicates the bottom topography within the upper 2,000 dbar. Vertical dash-dot lines and the labels A, A2, B, and C above indicate the locations of the Pressure-equipped Inverted Echo Sounder moorings; vertical dotted line and the GCM label indicates the nominal midpoint location of the moorings inshore of site A where the gridded current meter velocities are centered.

\subsection{SADCP Processing}

Upper ocean SADCP data were collected via a variety of hull-mounted Teledyne RD Instruments ADCPs (outlined in Table 2). These data were processed to a final state using the University of Hawaii's CODAS software package (currents.soest.hawaii.edu/docs/adcp_doc/codas_doc/). CODAS incorporates multiple heading sources when available to minimize errors induced by rapid heading changes and the effects of Schuler oscillations. The processed SADCP data from each cruise were binned temporally into 5-min averages. For the present analysis, these data are interpolated onto a consistent $10-\mathrm{m}$ vertical grid and averaged in horizontal bins of $0.02^{\circ}$ longitude width. Averages and standard deviations of the data from all cruises were then calculated using the gridded sections.

\section{Results}

\subsection{Mean and Standard Deviation of the Current Structure}

The average of the 16 LADCP velocity sections produces a "classical" picture of the Antilles Current (Figure 2), with peak meridional velocities near 400 dbar and near-zero velocities at the surface and near 900 dbar. Below 1,000 dbar, the uppermost parts of the DWBC are seen flowing southward beneath the offshore flank of the Antilles Current. The bulk of the Antilles Current is found west of the site B PIES, which is consistent with most of the studies along this line with moorings and ship sections in the 1980s and 1990s (e.g., Leaman \& Harris, 1990; Lee et al., 1990, 1996; Rosenfeld et al., 1989). The peak northward speeds of around $35-40 \mathrm{~cm} / \mathrm{s}$ are consistent with the shipboard Pegasus observations made in the late 1980s (Leaman \& Harris, 1990; Rosenfeld et al., 1989), but they exceed the peak speeds of $25-30 \mathrm{~cm} / \mathrm{s}$ from the current meter averages during the 1990s (Lee et al., 1990, 1996). More recent current meter observations from the start of the modern $26.5^{\circ} \mathrm{N}$ array found comparable $35-$ to $40-\mathrm{cm} / \mathrm{s}$ peak speeds in the Antilles Current (Johns et al., 2008). 


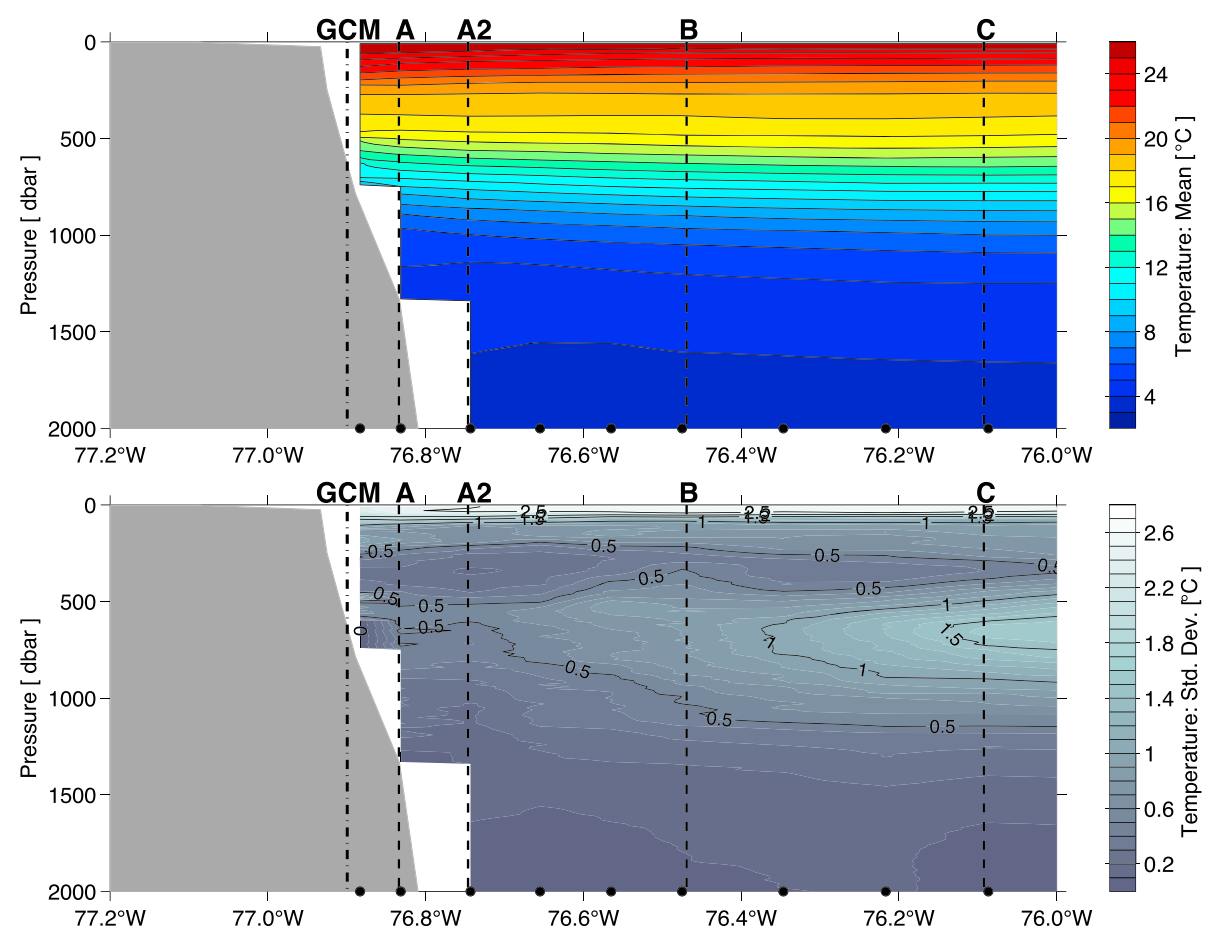

Figure 3. Average (top) and standard deviation (bottom) temperature sections from 16 cruises during 2005-2015. The locations of the Pressure-equipped Inverted Echo Sounder moorings are denoted by vertical dashed lines and letter designations along the top of each panel to aid in orientation; the nominal location of the inshore current meter gridded profile is shown by the vertical dash-dot line and the "GCM" label. The locations of the repeated ConductivityTemperature-Depth locations are shown by black dots along the bottom. Gray shading illustrates the bottom topography.

The meridional velocity variability captured by the LADCP sections is quite high, comparable to the peak mean speeds throughout the entire Antilles Current domain (Figure 2, bottom panel), demonstrating the high degree of variability within the region. Comparing the velocity variability with the mean and standard deviation of the temperature (Figure 3), salinity (Figure 4), and dissolved oxygen (Figure 5) from the concurrent CTD $-\mathrm{O}_{2}$ sections illustrates the simple fact that there is limited correspondence between the property sections and the velocity section, with minima in the property variabilities near the core of the Antilles Current flow and its associated variability. This suggests that a significant portion of the velocity variability at this location is barotropic and/or first-mode baroclinic in nature, despite the higher-order baroclinic structure of the Antilles Current itself (i.e., with a subsurface velocity maximum located away from both the sea surface and the sea floor).

The water masses of the North Atlantic are generally well known (although their nomenclatures can vary) and have been described in both temperature and density space (e.g., Emery \& Meincke, 1986; Schmitz \& Richardson, 1991; Worthington, 1959, 1976). For the purposes of this paper, dividing the water column into layers by isotherms rather than isopycnals is sufficient to descriptively delineate the water masses that are present in the upper $\sim 1,000 \mathrm{dbar}$, which encompasses the entire Antilles Current. Starting from the surface downward, these water masses consist of Atlantic Surface Water (ASW) above the $25^{\circ} \mathrm{C}$ isotherm, Subtropical Underwater (SUW) within the $19-25^{\circ} \mathrm{C}$ layer, North Atlantic Central Water (NACW) between the 19 and $8{ }^{\circ} \mathrm{C}$ isotherms, and finally, the upper portion of the Antarctic Intermediate Water (AAIW) between $8{ }^{\circ} \mathrm{C}$ and 1,000-dbar depth. The peak velocity $(>35 \mathrm{~cm} / \mathrm{s})$, denoting the core of the Antilles Current, is typically situated within the NACW layer at approximately $400 \mathrm{dbar}$ (Figure 2). A more focused characterization of the water properties found at this depth is sometimes referred to as North Atlantic Subtropical Mode Water or more commonly as " $18{ }^{\circ} \mathrm{C}$ Water" (EDW).

As can be seen in the temperature, salinity, and dissolved oxygen sections of Figures 3-5, the ASW is characterized by being warmer $\left(>25^{\circ} \mathrm{C}\right)$, fresher $(<36.6 \mathrm{psu})$, and slightly lower in dissolved oxygen $(<4.8 \mathrm{ml} / \mathrm{L})$ than the SUW directly beneath it. This narrow ASW layer is only approximately $50 \mathrm{dbar}$ thick, and the mean 


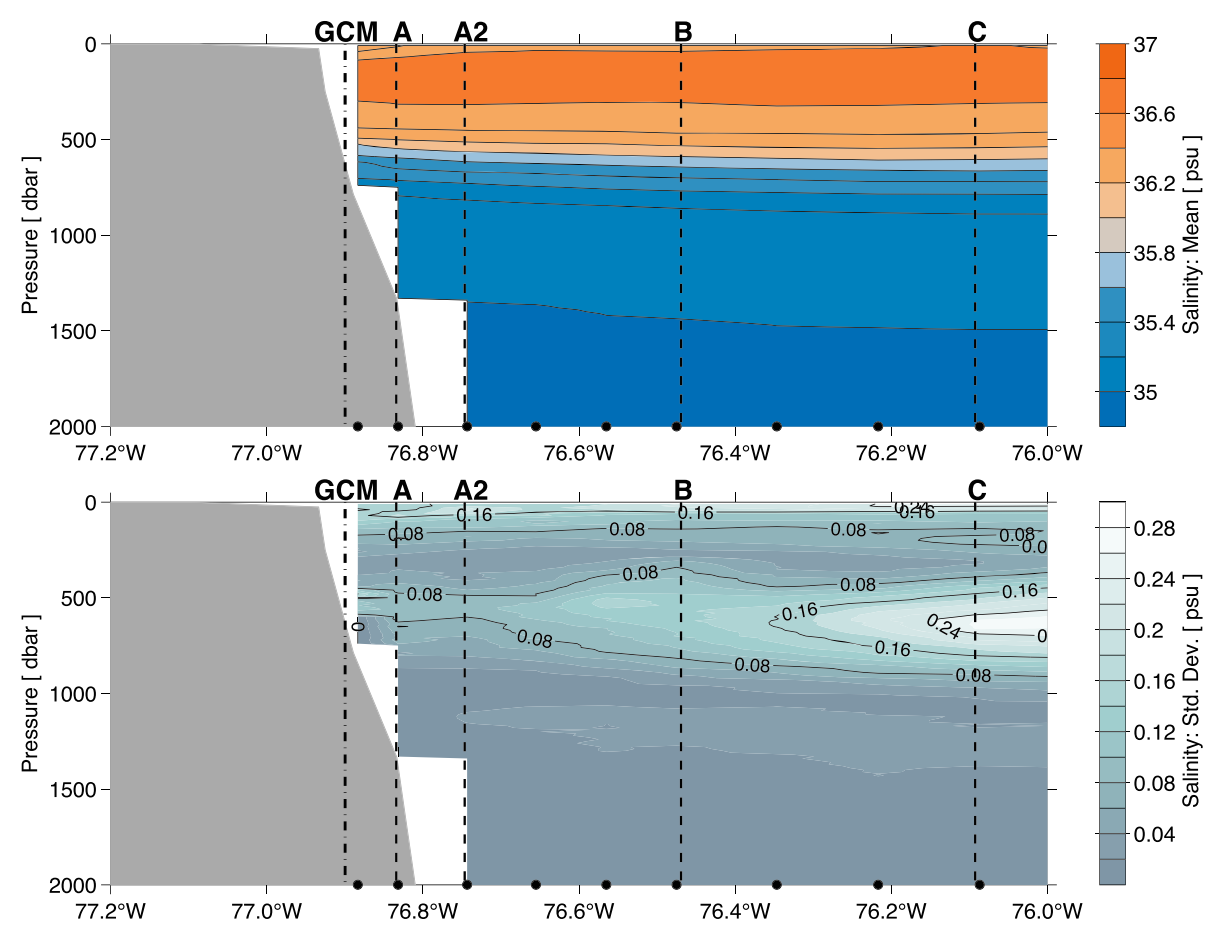

Figure 4. Average (top) and standard deviation (bottom) salinity sections from 16 cruises during 2005-2015. The locations of the Pressure-equipped Inverted Echo Sounder moorings are denoted by vertical dashed lines and letter designations along the top of each panel to aid in orientation; the nominal location of the inshore current meter gridded profile is shown by the vertical dash-dot line and the "GCM" label. The locations of the repeated Conductivity-Temperature-Depth locations are shown by black dots along the bottom. Gray shading illustrates the bottom topography.

velocity section shown in Figure 2 indicates that it is flowing southeastward, that is, counter to the Antilles Current flow, at up to $15 \mathrm{~cm} / \mathrm{s}$ in a narrow, shoreward-intensified band. Extending from just beneath these surface waters, SUW reaches depths of $\sim 300 \mathrm{dbar}$ and is characterized by its water column salinity maximum (with mean salinities in this layer reaching roughly $36.8 \mathrm{psu}$ ). It is also the most prevalent water mass above the Antilles Current core. Dissolved oxygen concentrations fall with depth through the SUW layer reaching an $\mathrm{O}_{2}$ minimum in the water masses beneath it, at the interface between NACW and AAIW. The NACW 19 to $8{ }^{\circ} \mathrm{C}$ temperature range typically falls between 300 and $800 \mathrm{dbar}$ and is characterized by a linear relation between temperature and salinity (both decreasing with depth). Dissolved oxygen within this layer decreases from $4.4 \mathrm{ml} / \mathrm{L}$ down to the water column oxygen minimum at the base of the layer (where values are $<3.4$ $\mathrm{ml} / \mathrm{L}$ ). AAIW can be found between 800 and $1,000 \mathrm{dbar}$, where temperatures are less than $8{ }^{\circ} \mathrm{C}$, salinity gradients weaken (35.2- to 35.0-psu range), and dissolved oxygen values begin to climb again from their minimum at the NACW-AAIW interface.

As is evident in the mean temperature (Figure 3), salinity (Figure 4), and dissolved oxygen (Figure 5) sections, the water-layer properties are, at first glance, fairly horizontally uniform across the Antilles Current and offshore flows when compared against the velocity field (Figure 2), especially as compared to the isoline tilts in other boundary currents such as the Gulf Stream (e.g., Figures 4-6 of Meinen \& Luther, 2016). Geostrophic velocity shears (i.e., thermal wind) require horizontal density gradients of course; the lack of visually obvious gradients in these property sections highlights the fact that very fine-scale variations produce the density structure associated with the Antilles Current. The variability of these sections as observed by their standard deviations (lower panels, Figures 3-5) reveals a region, coincident with the current's location indicated in the velocity section, of relatively stable temperature, salinity, and dissolved oxygen. Flows farther offshore in the subtropical gyre show much larger standard deviations of $\mathrm{T}, \mathrm{S}$, and $\mathrm{O}_{2}$.

In the vertical, the dissolved oxygen section (Figure 5) and, to a lesser extent, the salinity section (Figure 4) also show variability maxima just below the 1,000 dbar base of the Antilles Current, although there is no corresponding maximum in temperature variability at this depth (Figure 3 ). This may be due to the fact that the 


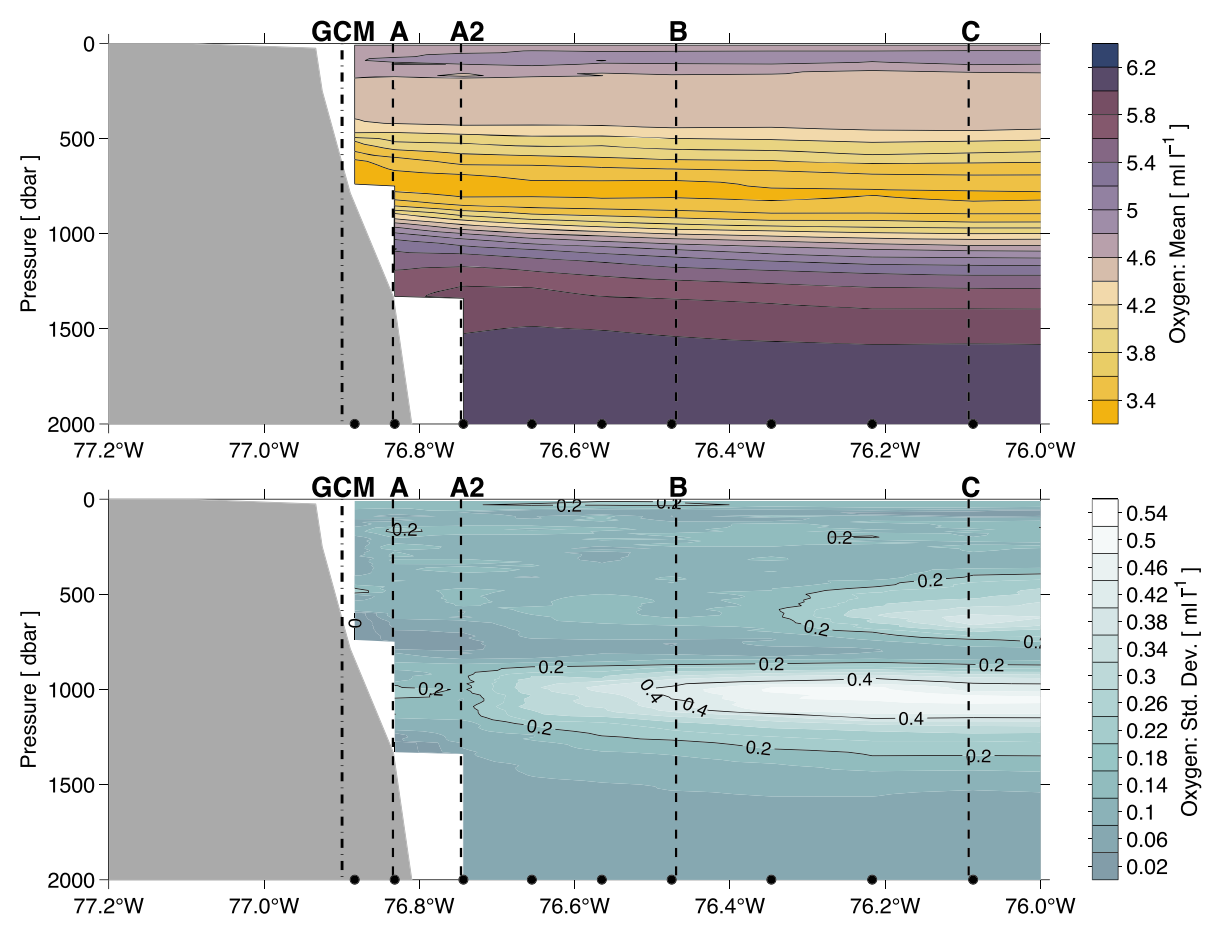

Figure 5. Average (top) and standard deviation (bottom) dissolved oxygen sections from 16 cruises during 2005-2015. The locations of the Pressure-equipped Inverted Echo Sounder moorings are denoted by vertical dashed lines and letter designations along the top of each panel to aid in orientation; the nominal location of the inshore current meter gridded profile is shown by the vertical dash-dot line and the "GCM" label. The locations of the repeated Conductivity-

Temperature-Depth locations are shown by black dots along the bottom. Gray shading illustrates the bottom topography.

upper part of the southward-flowing DWBC, with very different water properties, lies just below and slightly offshore of the bottom of the Antilles Current, and there are likely vertical motions of the isopycnals associated with these dynamic currents that affect the water mass content along any given isopycnal lying between the two. Recall, however, that the velocity variability is quite low at 1,000 dbar relative to other depths (Figure 2), so the variations on the density surfaces are likely to be fairly uniform zonally though the region.

Comparing the mean velocity structure as observed by all five measurement systems used in this study illustrates the robustness of this mean structure (Figure 6). Despite some earlier studies suggesting that the Antilles Current might not exist in a time-mean sense (e.g., Gunn \& Watts, 1982), clearly these observations from five different measurement systems, including two systems (current meters and PIES) involving more than 10 years of daily data, indicate that the Antilles Current does have a mean presence, at least at this location. The high degree of variability observed (e.g., Figure 2) suggests that the earlier studies may have simply had insufficiently long records and/or insufficient numbers of repeated ship sections. The existence of a mean Antilles Current at this location is not a new result, as shorter time series had demonstrated a mean current previously (e.g., Johns et al., 2008; Lee et al., 1990, 1996). The key result here is that in using five different observation methods and much longer time series, the resulting confidence in the mean Antilles Current velocity cross section is higher than has been possible in the past.

Another important fact, perhaps the most unexpected and interesting result of this study, is evident when the mean velocity sections from the five different systems are compared in more detail. Integrating the velocity horizontally in the "core" of the Antilles Current domain between sites A and A2 (the two westwardmost PIES sites), a distance of about $5 \mathrm{~nm}$ (or $9 \mathrm{~km}$ ), illustrates some important differences between the resulting transport-per-unit-depth profiles (Figure 7a). Consider initially the averages of the full 10.5-year records from the current meters and the PIES (blue and red solid lines, respectively). The profiles intersect perfectly at 1,000 dbar-recall that the gridded current meter at 1,000 dbar was used to provide the absolute 

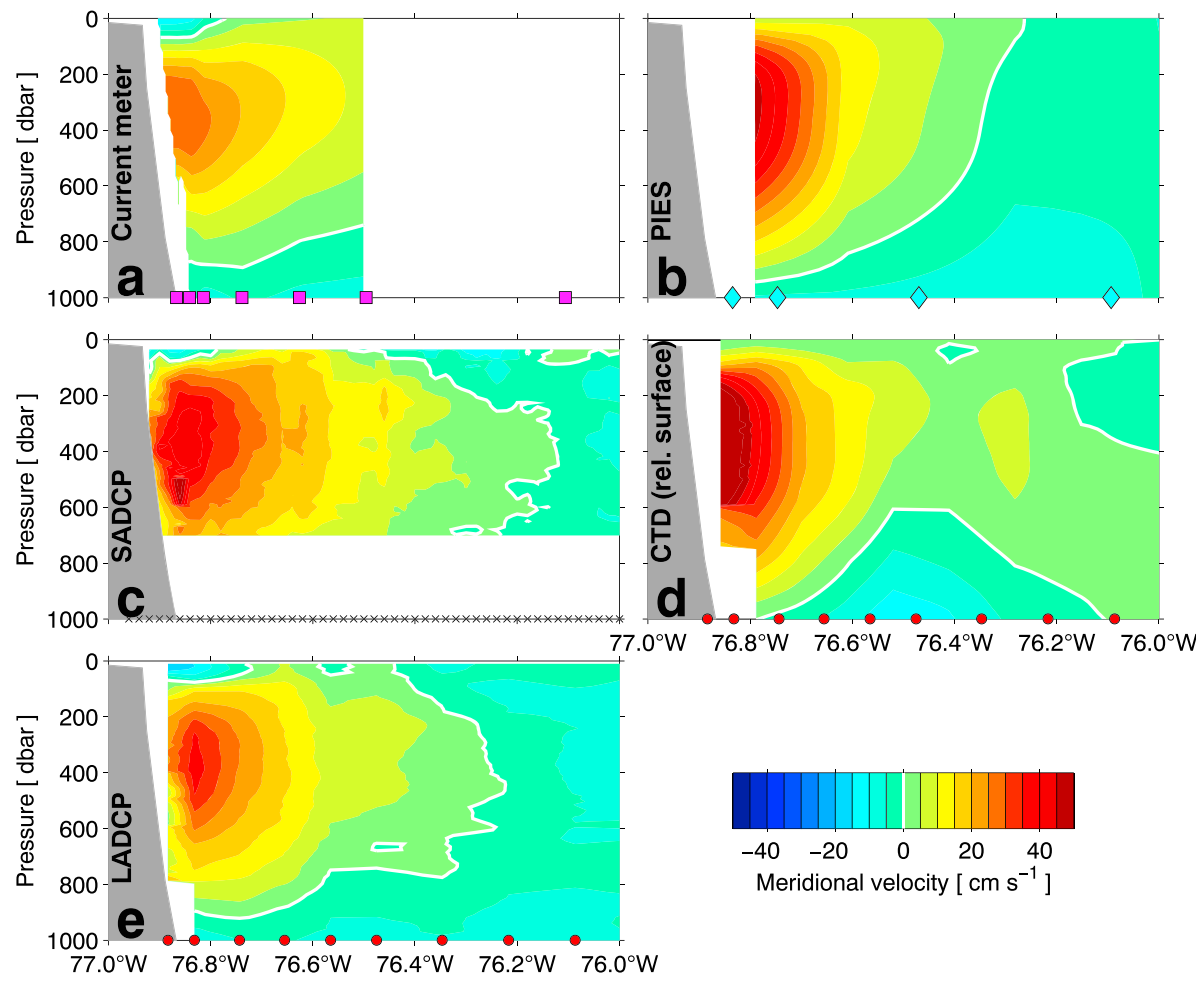

Figure 6. Average sections of meridional velocity determined by averaging all of the data available from the various observing systems over the 2005-2015 time period described in this study. Positive values indicate northward flow, with the zero contours indicated by the bold white lines. (a) Average of the 12-hourly gridded current meter data, with the mooring locations indicated along the lower axis. Note the easternmost mooring shown on the plot only had current meters on it beginning in 2014, so those data are not used in gridding the velocities. (b) Average of the daily PIES velocities processed as described in the text, with the PIES locations indicated along the lower axis. (c) Average of 13 SADCP sections (see Table 3), with all sections individually gridded to the points indicated on the lower axis before the averaging. Note that most of the sections only obtained data down to about $700 \mathrm{dbar}$, so below that averages are not shown. (d) Average of the geostrophic velocity sections, all relative to an assumed level of no motion at the surface, derived from 16 CTD sections (see Table 3), with the station locations indicated along the lower axis. (e) Average of 16 LADCP sections (see Table 3), with the station locations indicated along the lower axis. PIES = Pressure-equipped Inverted Echo Sounder; SADCP = Shipboard Acoustic Doppler Current Profiler; LADCP = Lowered Acoustic Doppler Current Profiler; CTD = Conductivity-Temperature-Depth.

velocity reference for the PIES-estimated relative velocity profiles. Therefore, the exact agreement at that level is by construction; as at that one level, the two data sets are not independent. At all other depths, however, the two are completely independent of one another. And, as is evident, the vertical shear in the PIES mean transport profile above 1,000 dbar (i.e., the difference in the observed transport at 1,000 dbar and the peak transport) is much stronger than that of the current meters. Both profiles reach a peak velocity near $400 \mathrm{dbar}$; however, the PIES-based profile has a much larger maximum value at that depth, and it demonstrates a much broader peak that is nearly $300 \mathrm{dbar}$ wide in the vertical. The gridded current meter data have a weaker vertical shear above the 400 dbar maximum as well (i.e., the difference between the transport at $400 \mathrm{dbar}$ and the ocean surface); however, because the peak current meter transport value is so much smaller than that of the PIES, the near-surface value is lower for the current meter. In fact, the current meter data suggest a weak reversal to southward flow. This thin southward flow layer is likely real; however, it should be noted that the process of gridding the current meter and moored ADCP velocities includes an extrapolation up to the sea surface through the $\sim 30 \mathrm{~m}$ "shadow zone" (a portion of the water column directly beneath the surface in which acoustic reflections obscure the water velocity signal). The WB-1 and WB-2 moorings do not have upward-looking ADCPs-their top measurement is nominally at $100 \mathrm{~m}$, so there is more extrapolation vertically at those sites than at WB- 0 . When the moorings "blow over" due to strong currents, this extrapolation layer can become much larger. 

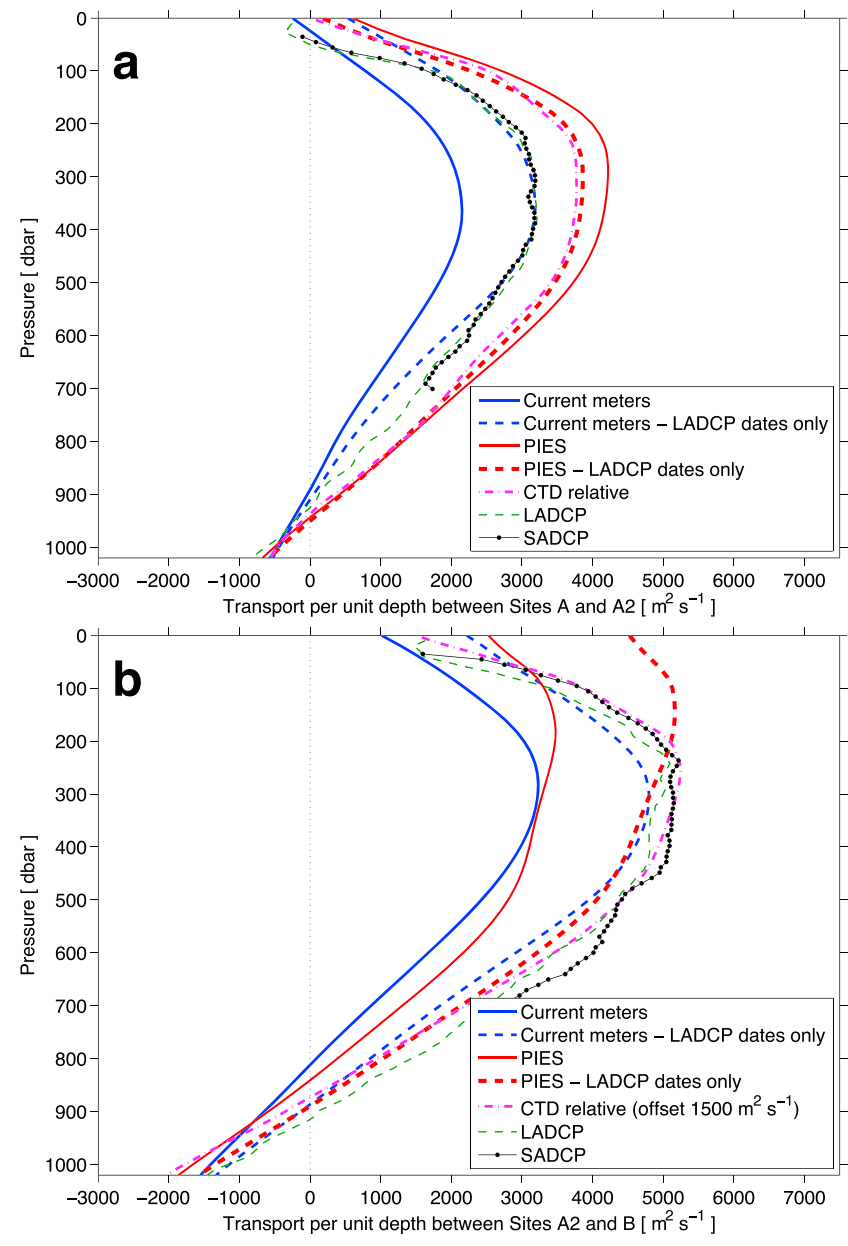

Figure 7. Comparison of the time-mean transport per unit depth integrated horizontally between (a) sites A and A2 and (b) between sites A2 and B, using the different measurement systems discussed in the text. The time mean over the full 10.5-year record is shown for the current meter (blue solid) and the PIES-current meter hybrid (red solid); also shown are the averages from the SADCP (black dotted), LADCP (green dashed), and CTD (magenta dash dot), the latter determined as the geostrophic transport relative to an assumed level of no motion at the surface. Finally, the results from the moored instruments are shown (as red and blue dashed lines) when the data are averaged only on the 13 days when the cruises were observing this span (i.e., the days corresponding to the cruises where SADCP, LADCP, and CTD were available). In (b), the CTD relative profile was offset by a positive $1,500 \mathrm{~m}^{2} / \mathrm{s}$ to compare with the other profiles. PIES $=$ Pressure-equipped Inverted Echo Sounder; SADCP $=$ Shipboard Acoustic Doppler Current Profiler; LADCP = Lowered Acoustic Doppler Current Profiler; CTD $=$ Conductivity-Temperature-Depth .
Adding the average of the integrated transport profiles from the LADCP, SADCP, and the calculated geostrophic velocities between the CTD pair further illustrates some important differences (green dashed, black solid with dots, and magenta dash-dot lines in Figure 7, respectively). Comparing these three profiles to the averages of the full 10.5-year records from the PIES and current meters is somewhat inappropriate, given the fact that there are only a very limited number of sections that are being averaged (less than 20) for each type of ship section data (i.e., the dates of the $<20$ cruises represent only about $0.4 \%$ of the total number of days encompassed within the mooring records). A more appropriate approach is to average the PIES and current meter data only on the days when the area between sites A and A2 was being observed by the ship sections (red dashed and blue dashed lines in Figure 7, respectively). Several exciting results quickly jump out of this comparison. First, there is generally quite good agreement between the direct velocity methods (current meter, LADCP, and SADCP), and there is quite good agreement between the geostrophy-based methods (PIES and CTD), which provides confidence in both the interpolation/extrapolation/gridding methods for the current meter data and the GEM analysis of the PIES data. Notice in particular that both of the geostrophy-based profiles have a much stronger peak transport value than the three direct velocity methods. Second, the vertical shear in the current meter average is stronger than is found in the LADCP and SADCP below the velocity maximum (i.e., between 400 and $1,000 \mathrm{dbar}$ ), and the current meter vertical shear is weaker than is found in the LADCP and SADCP above the velocity maximum (i.e., above 400 dbar). By contrast, the vertical shear in the PIES profile is very similar to that in the CTD data both above and below the maximum. Keep in mind that while the CTD data from these sections was used to build the GEM fields that provide the vertical structure information for the PIES estimates, the CTD casts collected at the locations of sites A and A2 during these 16 sections represent less than $8 \%$ of the hydrographic data used to create the GEM fields, so the PIES and CTD profiles are mostly independent.

Integrating the transports between the moorings at sites A2 and B, essentially through the offshore flank of the Antilles Current, gives a different result (Figure 7b). This span is significantly wider than the span between sites A and A2, roughly $28 \mathrm{~km}$ versus $9 \mathrm{~km}$, and what is immediately evident is that there is much less of a difference between the velocity structures from the direct and geostrophic systems. Focusing on the averages during the dates of the ship sections, all of the systems are producing roughly the same profile. The lone exception is the PIES estimate, which appears to significantly underestimate the shear between about $250 \mathrm{dbar}$ and the surface and which places the maximum about $100 \mathrm{dbar}$ too shallow compared to the other observations. The 10.5-year means from the current meters and the PIES are much more similar as well, although again, the PIES seems to be underestimating the shear in the upper $\sim 250 \mathrm{dbar}$. One might argue that the current meters might be underestimating the shear between $\sim 900$ and $\sim 500$ dbar on the bottom of the Antilles Current, with both the 10.5-year mean (blue solid line) and the average on the days of the cruises (blue dashed line) being a bit lower than the corresponding values from the other data sets. However, the differences in this span (Figure 7b) are much smaller than the differences in the core of the Antilles Current (Figure 7a).

Several conclusions can be drawn from the comparisons in Figure 7. First, based on the fact that the direct velocity methods all agree with one another within the core of the Antilles Current (Figure 7a) and all of them observe flows lower than the two geostrophic methods, it seems that the Antilles Current is not 
perfectly characterized by geostrophy in a time-mean sense. While one could argue that the problem might be that the horizontal resolution of the current meters is insufficient and the gridded velocity fields derived from them are too smooth, the resolution of the current meter moorings in this span is excellent (three moorings within $\sim 9 \mathrm{~km}$ ), so this would be hard to imagine. And furthermore, horizontal resolution is clearly not an issue for the SADCP sections as the SADCP has a near-continuous horizontal resolution, and the SADCP and current meters show essentially the same mean profile. One might also argue that the problem is that the GEM analysis of the PIES data as based on a limited hydrographic database, however, that would not explain the close agreement between the PIES and the CTD mean profiles. The fact that the average of the 13 days of PIES data during the cruises is weaker than the 10.5-year PIES time series mean, while the average of the 13 days of current meter data during the cruises is stronger than the 10.5-year current meter time series mean is interesting - this seems likely to be an issue of the differing amplitudes between the PIES and current meter data, as it will be shown shortly that the correlations between the variations in the two data sets are very high. The fact that this disparity between direct and geostrophic estimation systems does not hold on the flank of the Antilles Current between sites A2 and B (Figure 7b) suggests that this disagreement may be most pronounced in the core of the current.

A second result suggested by these comparisons of the current meter profiles to the LADCP and SADCP profiles is that it appears that the vertical extrapolation of the current meter data to the surface on these 13 days may be underestimating the vertical shear in the transport above $100 \mathrm{dbar}$ (cf. blue dashed with green dashed and black solid with dot lines in Figure 7a). If this is true over the full 10.5-year period, the reversal in flow very close to the surface observed in the full 10.5-year mean of the current meter record (blue solid line in Figure 7a) might in reality be an even stronger reversal to southward flow. This near-surface difference does not appear as strongly within the flanks of the Antilles Current (Figure 7b), although there is some hint of disagreement in the shear in the upper $\sim 100$ dbar in that span as well. Recall also that the SADCP and LADCP averages in Figure 7 are from only the 13 cruises when all data sets were available, while the averages in Figure 6 are of all available data (up to 16 cruises), so disagreement between those averages is to be expected. Finally, the "width" of the velocity peak in a vertical sense seems to be narrower in the direct velocity methods than in the geostrophy-based methods within the core of the Antilles Current (Figure 7a), perhaps suggesting once again that while the Antilles is clearly fairly well characterized by geostrophy, some departure from geostrophic balance may be present. Alternatively, it may be suggested that this is still related to insufficient horizontal and/or vertical resolution in the direct velocity observations, although this seems unlikely given the breadth of data applied here, or some inadequacy in the GEM fields used for the PIES analysis, although that would not explain the close agreement between the PIES data and the CTD data.

\subsection{Propagation Across the Array}

Previous observational analyses of the DWBC below/offshore of the Antilles Current at this latitude have demonstrated that the largest transport fluctuations are the result of westward propagating Rossby Wavelike features (e.g., Lee et al., 1996; Meinen \& Garzoli, 2014), and a recent model analysis has also shown how these propagating features might impact the flow of the Antilles Current (Domingues et al., 2019). The PIES-GEM estimated temperatures and salinities provide another set of observations that can be utilized to evaluate propagation of signals through the array (Figure 8). Correlations between the estimated temperatures and salinities at 400 dbar, roughly at the center (vertically) of the Antilles Current, clearly illustrate the signature of westward propagation through the array (Figures $8 \mathrm{a}$ and $8 \mathrm{c}$ ). The time series of temperature and salinity at sites A through D have roughly 90 degrees of freedom (e.g., Emery \& Thomson, 1997) in them, so correlations greater than $r=0.2$ are statistically significant at the $95 \%$ level. Based on the observed leads/lags for the maximum correlations (Figures $8 \mathrm{~b}$ and $8 \mathrm{~d}$ ), the westward propagation of the dominant signals at this pressure level is roughly 7-9 km/day between sites A2, B, and C, and it is slightly slower, around $5 \mathrm{~km} /$ day, between sites $\mathrm{C}$ and $\mathrm{D}$. The maximum correlation between the signals observed at sites $\mathrm{A}$ and $\mathrm{A} 2$ is at a lag of 0 days. This is consistent with the 7-9 km/day propagation speed and the $\sim 9 \mathrm{~km}$ spacing between sites when one recalls that the time series data sets used herein have all been smoothed with 48- to 72-hr low-pass filters.

These westward propagation speeds of roughly $9 \mathrm{~cm} / \mathrm{s}$ are larger than the 5 to $7 \mathrm{~cm} / \mathrm{s}$ estimated previously for the westward propagating features by Meinen and Garzoli (2014), possibly reflecting more robust statistics given the fact that the time series being analyzed here are twice as long as those that were used in that 

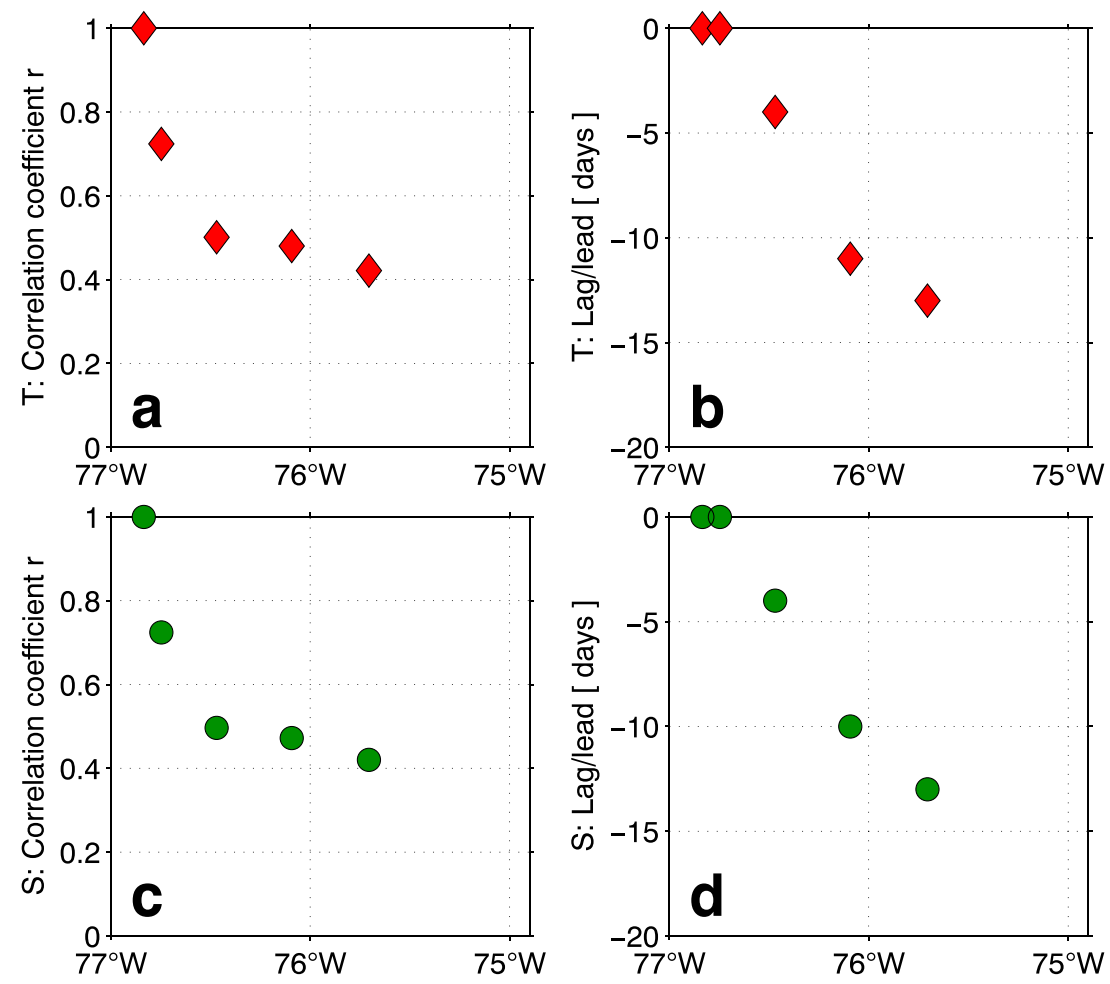

Figure 8. Lag/lead correlations of temperature and salinity at 400 dbar across the array. (a) Correlation coefficient between the pressure-equipped inverted echo sounder-Gravest Empirical Mode estimated temperature at 400 dbar at site A and the corresponding temperatures at the other sites; (b) lag/lead where the maximum correlation is found; (c) as for (a) but for salinity at $400 \mathrm{dbar}$; (d) as for (b) but for salinity at $400 \mathrm{dbar}$. Correlations are shown for pressure-equipped inverted echo sounder sites A, A2, B, C, and D (see Table 1 for locations); correlations for site E are not shown as they are not statistically significant at even the $67 \%$ level $(r<0.2)$. Negative lag/lead indicates the offshore site is leading the variations at site $\mathrm{A}$.

earlier study. The observed westward propagation speed is also faster than would be expected based on theoretical first-mode baroclinic Rossby Waves, but previous observations with satellite altimetry (e.g., Chelton \& Schlax, 1996; Osychny \& Cornillon, 2004) and earlier moorings in this region (Lee et al., 1996) have similarly found slightly faster-than-theory propagation speeds for these types of features. The existence of these westward propagating features is certainly not a new discovery; however, the time series used herein are perhaps the longest in situ records that have been used for this calculation, and so the results presented here are solid confirmation of those earlier analyses. These results also demonstrate that these propagating features are providing a dominant source of the temperature and salinity variability within the core of the Antilles Current, possibly simply through vertical displacements of the main thermocline/halocline, which has not been noted in the past.

\subsection{Transport of the Antilles Current}

Because it is the naturally integrating method-and hence should arguably be "better" for calculating transports- unless it is stated otherwise, in what follows the geostrophy-based estimates are used for the transport calculations wherever possible. As will be illustrated shortly, the temporal variability characteristics of the geostrophic and current meter transports are quite similar, and these temporal character results are not sensitive to which record is used, although, as noted earlier, there is a difference in the time-mean flows from the two systems (e.g., Figure 7). In what follows the transports are all integrated between the surface and 1,000 dbar, as the mean sections all indicate that the mean flow is near zero at that depth (e.g., Figure 6). Historical observations of the Antilles Current have likewise found the lower boundary of the flow to be at roughly 1,000 dbar (e.g., Bryden et al., 2005; Johns et al., 1997; Leaman \& Harris, 1990; Lee et al., 1990). The temporal variability of the resulting transports is not sensitive to small (50-100 dbar) changes to this deeper integration limit. 
Table 3

Transport Statistics-All Transports Integrated Horizontally as Noted in the Left Column (see Table 1 for Site Locations) and Integrated Vertically Above 1,000 dbar or Above the Bottom Wherever It Is Shallower Than 1,000 dbar

\begin{tabular}{|c|c|c|c|c|c|c|}
\hline Span & Mean transport & Maximum transport & Minimum transport & Standard deviation & Integral time scale & Span width \\
\hline Inshore of site A & $+0.2 \mathrm{~Sv}$ & $+1.0 \mathrm{~Sv}$ & $-0.8 \mathrm{~Sv}$ & $0.3 \mathrm{~Sv}$ & 14.7 days & $13 \mathrm{~km}$ \\
\hline Between sites A \& A2 & $+2.6 \mathrm{~Sv}$ & $+13.3 \mathrm{~Sv}$ & $-6.2 \mathrm{~Sv}$ & $2.7 \mathrm{~Sv}$ & 22.2 days & $8.9 \mathrm{~km}$ \\
\hline Between sites A2 \& B & $+2.0 \mathrm{~Sv}$ & $+19.0 \mathrm{~Sv}$ & $-27.9 \mathrm{~Sv}$ & $6.0 \mathrm{~Sv}$ & 24.6 days & $27.5 \mathrm{~km}$ \\
\hline Between sites B \& C & $-1.4 \mathrm{~Sv}$ & $+32.0 \mathrm{~Sv}$ & $-37.9 \mathrm{~Sv}$ & $7.7 \mathrm{~Sv}$ & 44.5 days & $37.4 \mathrm{~km}$ \\
\hline $\begin{array}{l}\text { Coastline out to site B } \\
\text { (i.e., the "Antilles } \\
\text { Current transport") }\end{array}$ & $\begin{array}{c}+4.7 \mathrm{~Sv} \\
(\mathrm{CM}: 2.9 \mathrm{~Sv})\end{array}$ & $\begin{array}{c}+28.6 \mathrm{~Sv} \\
(\mathrm{CM}: 19.6 \mathrm{~Sv})\end{array}$ & $\begin{array}{c}-23.7 \mathrm{~Sv} \\
(\mathrm{CM}:-13.8 \mathrm{~Sv})\end{array}$ & $\begin{array}{r}7.5 \mathrm{~Sv} \\
(\mathrm{CM}: 5.3 \mathrm{~Sv})\end{array}$ & $\begin{array}{c}19.0 \text { days } \\
\text { (CM: } 18.7 \text { days) }\end{array}$ & $49.4 \mathrm{~km}$ \\
\hline
\end{tabular}

Note. Transport values are reported in units of Sverdrups; integral time scale is reported in units of days; span width is reported in units of kilometers. Span inshore of site A is from gridded current meters; spans between A \& A2 and between A2 \& B are based on the "hybrid" PIES geostrophic transport reference with the gridded current meter; and the span between B \& C is based on PIES geostrophy for both relative and reference terms. Values for coastline to site B are based on the methods mentioned above for the four spans, with the values from the gridded current meters only provided in parentheses. $\mathrm{CM}=$ current meter.

The time-mean transport of the Antilles Current appears to be roughly equally split between the spans between sites A and A2 and between sites A2 and B, with the flow in the former span being slightly larger (Table 3). The temporal variability (as quantified by the standard deviation) in the sites A2 to B span is more than a factor of 2 larger than that in the sites A to A2 span, perhaps because the former span itself is roughly a factor of three wider than the latter. The integral time scale (e.g., Emery \& Thomson, 1997) of the flow in these two spans is nearly equal (22.2 days vs. 24.6 days), which suggests that similar dynamics are dominating the flow variability in these two spans. Inshore of site A, where the flow can only be determined from the gridded current meter and moored ADCP data from moorings WB-ADCP and WB-0 (Table 1), the transport is very weak in both a mean $(0.2 \mathrm{~Sv})$ and standard deviation $(0.3 \mathrm{~Sv})$ sense. The variability inshore of site $\mathrm{A}$ is a bit higher frequency (integral time scale of only 14.7 days), but the weak standard deviation suggests that the flow up on the continental shelf contributes in only a small way to the overall Antilles Current variability. Between sites B and C, the mean transport reverses and becomes weakly southward, consistent with the ship section averages that indicate that most of the Antilles Current flows are found west of site B (e.g., Figures 2 and 6). Historical observations at this same latitude have similarly shown that the mean Antilles Current is primarily found inshore of the longitude of site B (e.g., Lee et al., 1990, 1996). The variability within the span between sites $\mathrm{B}$ and $\mathrm{C}$ is even larger than that in the more inshore spans, and the integral time scale of the flow between sites B and C is nearly a factor of two longer (44.5 days). This suggests that the flow in this span is dominated by processes with different physics than in the inshore spans. For the purposes of this study, therefore, the Antilles Current transport will be defined as the flow from the coastline out to site $\mathrm{B}$ and between the surface and 1,000 dbar.

The resulting time-mean Antilles Current transport, determined by combining the current meter-based estimates inshore of site A (moorings WB-ADCP and WB-0; see Table 1) with the PIES-based estimates between sites $\mathrm{A}$ and $\mathrm{B}$ (referenced with the current meter data at 1,000 dbar), will be referred to hereafter as the "PIES-hybrid" time series (Table 3). The record-length mean transport is $4.7 \mathrm{~Sv}$, which falls near the middle of the range of historical estimates (e.g., 3.2 Sv from Lee et al., 1990; 5.0 Sv from Lee et al., 1996; 6.1 Sv from Meinen et al., 2004; 5.1 Sv from Bryden et al., 2005; 6.0 Sv from Johns et al., 2008; and 1.2 Sv from FrajkaWilliams et al., 2013). The estimated measurement accuracy of the daily values is $2.1 \mathrm{~Sv}$, while the record length mean is estimated to be accurate to within $1.7 \mathrm{~Sv}$ (using here a "first principles" error estimation method; see Appendix B). The 4.7-Sv mean Antilles Current transport is more than a factor of 5 smaller than the $~ 32-S v$ Florida Current transport flowing northward farther west in the northern Straits of Florida (e.g., Meinen et al., 2010). Over this roughly 10.5-year record, the transport of the Florida Current and the Antilles Current are not significantly correlated with one another $(r=0.14)$ given the $\sim 85$ degrees of freedom in the Antilles Current record ( 22.5-day integral time scale and two integral time scales per degree of freedom). The correlation remains insignificant even after low-pass filtering the time series with $30(r=0.15)$ or 90 day $(r=0.14)$ cutoff periods. Lagged correlations remain very low $(r<0.25)$ for all lags or leads up to half the record length. So while over limited periods there have been indications of correlation between the Antilles Current and Florida Current variability at this location (e.g., Frajka-Williams et al., 2013), there is 

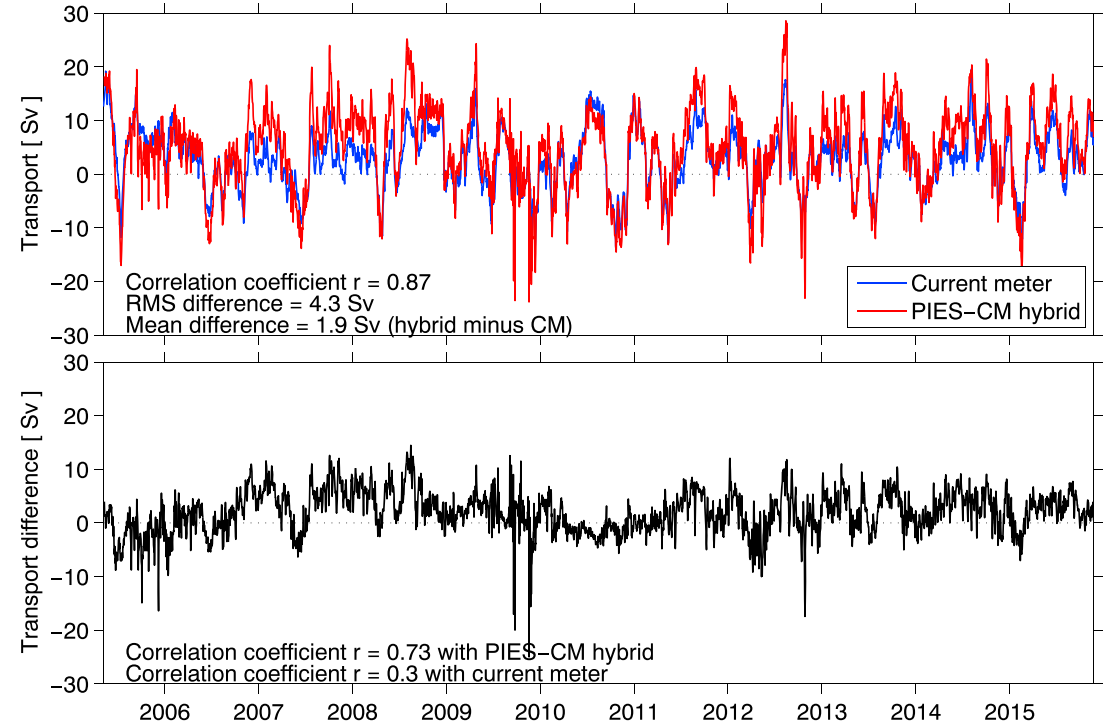

Figure 9. (top) Antilles Current transport (as defined in this paper), that is, the transport integrated in the upper 1,000 dbar (or above the bottom where it is shallower than 1,000 dbar) and between the Abaco Island coastline out to site B. The transports estimated using both the pure gridded current meter data (blue line) and the "hybrid" computation using the PIES-Gravest Empirical Mode-based geostrophic estimates between sites A and B (red line) are shown. (bottom) The difference between the two time series in the upper panel (determined as the PIES-CM hybrid minus the current meter) is plotted. In each panel, some basic statistics are shown: In the top panel, it is the correlation coefficient between the two time series, as well as the RMS and record-length-mean differences; in the bottom panel, it is the correlation coefficient between the plotted difference time series and the original time series from the top panel. RMS = root-meansquared; $\mathrm{CM}=$ current meter; PIES = pressure-equipped inverted echo sounder.

not a consistent pattern of correlation between the two neighboring flows in this longer time series, and individual events are likely the source of sporadic-correlated variability. Previous analyses have shown that Rossby Waves and other westward propagating features do impact both currents and that these features can "pass through" the Bahamas Island chain via complicated wall jets and other mechanisms (e.g., DiNezio et al., 2009; Domingues et al., 2016, 2019). Such westward propagating features have been shown to dominate the largest amplitude transport fluctuations of the DWBC just offshore of the Antilles Current at $26.5^{\circ} \mathrm{N}$ (e.g., Meinen \& Garzoli, 2014), and it is to be expected that they would also have large impacts on the Antilles Current transport variability.

The Antilles Current transport time series indeed shows large variations at a wide range of time scales (Figure 9), with a peak-to-peak range of $52.3 \mathrm{~Sv}$ (33.3 Sv for the current meter data) spanning between a maximum northward transport of $28.6 \mathrm{~Sv}$ (19.6 Sv for the current meter data) and a maximum southward transport of $-23.7 \mathrm{~Sv}(-13.8 \mathrm{~Sv}$ for the current meter data). The observed variations in the Antilles Current transport (PIES-hybrid standard deviation $=7.5 \mathrm{~Sv}$ ) exceed those of the basin-wide meridional overturning circulation measured at the same latitude - the standard deviation of the latter (after a 10-day low-pass filtering) is only about $2 \mathrm{~Sv}$ (e.g., Smeed et al., 2018). The PIES-hybrid standard deviation of 7.5 Sv decreases only slightly to $7.3 \mathrm{~Sv}$ if the record is smoothed with a 10-day low-pass filter similar to that used on the basin-wide meridional overturning circulation estimate. As noted earlier, the character of the Antilles Current transport time series (e.g., variability and phasing) is essentially the same regardless of whether the transport is integrated using only the gridded current meter data or is calculated using the geostrophic estimates from the PIES where available (blue and red lines in Figure 9, respectively). The two time series are correlated at $r=0.87$, and the correlation is essentially the same after 30- and 90-day low-pass filtering ( $r=0.90$ and $r=0.87$, respectively; second-order Butterworth filter passed both forward and back). Interestingly, the difference between the two time series (Figure 9, lower panel) is significantly correlated ( $r=0.73$ ) with the PIES hybrid time series. This indicates that the difference is unlikely to be due to an independent source of variability, such as wind-stress-driven Ekman flow (which is quite small in this narrow span; less than $0.02 \mathrm{~Sv}$ ). Instead, much of the difference must be the result of an amplitude bias (i.e., the 


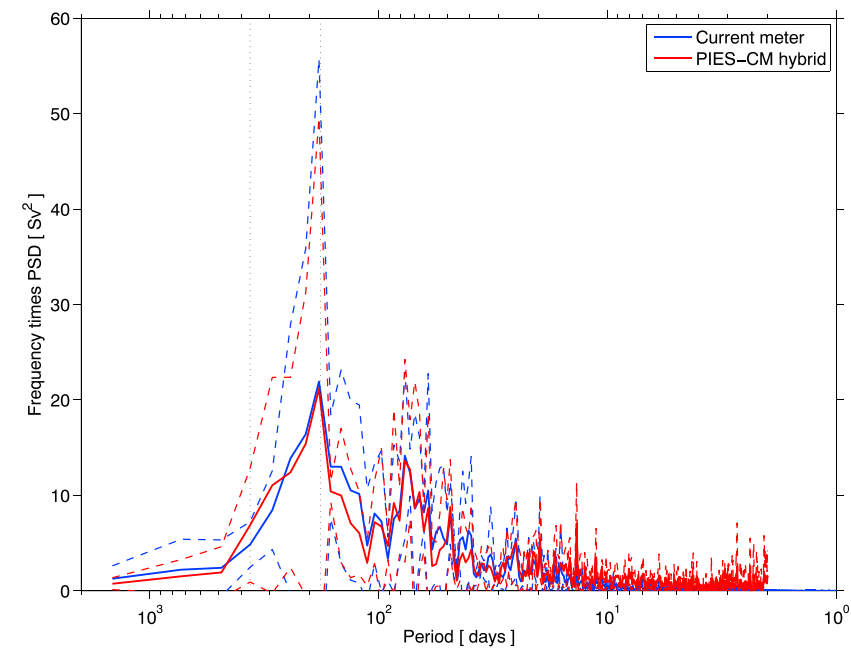

Figure 10. Variance preserving spectra of the Antilles Current transport (integrated from the coast out to site B and above 1,000 dbar or the bottom where shallower) using either the gridded current meter data (blue) or the hybrid geostrophy record described in the text (red). Blue and red dashed lines indicate 95\% confidence limits for the CM and hybrid spectra, respectively. Spectra are calculated using the Welch's averaged periodogram method. PIES = pressure-equipped inverted echo sounder; $\mathrm{CM}=$ current meter; PSD = power spectral density. sign of anomalies in the two records are generally the same, but the amplitude of one is consistently larger than the amplitude of the other). The geostrophic flow variability is routinely higher amplitude, which is consistent with the time-mean profile presented earlier (Figure 7). The temporal standard deviation of the transport (PIES-hybrid) over the 10.5 years was 7.5 Sv, which is quite similar to the temporal standard deviations that were found with current meter arrays at this location in the late 1980s and early-mid-1990s (7.6 Sv from Lee et al., 1990; 9.0 Sv from Lee et al., 1996); however, those earlier studies defined the Antilles Current as transports integrated out to the location of site $\mathrm{C}$, a significantly wider integration domain. The fact that the 5.3-Sv standard deviation of the current meter-only transport presented herein (Table 3) is somewhat smaller than the previous mooring arrays reflects this narrower integration domain. The earlier arrays in the 1980s and 1990s had a coarser horizontal spacing of the moorings, which may also account for some of the difference in observed current meter variability-or of course, it could be a result of temporal difference between the 1980s-1990s and the 2000s-2010s.

Spectral analysis of the Antilles Current transport time series, for both the PIES-hybrid and current meter only estimates, yields very similar variance preserving spectra (Figure 10). The spectra are nearly identical, and all differences are well within the $95 \%$ accuracy estimates determined using the Welch's averaged periodogram method (e.g., Emery \& Thomson, 1997) with a 4-year window allowing 2 years of overlap. The spectra show strong peaks at the semiannual period; however, the error estimates for the spectra at this period are also very high, easily encompassing zero energy as being possible within 95\% confidence limits. Significantly less energy is indicated at the annual period, with no obvious spectral peak at that period. The transport record shows a relatively broad band of higher energy at periods ranging from 40 to 400 days, with the only obvious peaks centered at 180 and 77 days (the former peak having very large error bars, as noted above). Spectral analysis of the Antilles Current transport has only previously been reported by Lee et al. (1996), who used several 1- to 2-year records from current meter arrays in the late 1980s and early 1990s. Those shorter records found a dominant energy peak at periods of roughly 100-150 days with a secondary peak centered roughly at 30 days. There is no evident 30-day peak in either the PIES-hybrid or current meter transport records presented herein nor is there a peak in either spectra centered anywhere near 100-150 days (Figure 10). The spectra presented in Lee et al. (1996) had no error bars; however, it seems most likely that the error bars were large given the error estimates presented herein based on much longer records. As such, the difference in these new results versus the earlier analysis of Lee et al. (1996) is likely attributable to the much longer record (and hence more windows in the spectral computation) in the newer record; the horizontal resolution of the mooring array is also finer in the modern experiment. Given the very large error bars on the calculated spectra, one must use caution in interpreting the transport spectra; obviously, a wide range of phenomena at a broad range of temporal scales is impacting the transport variability. The spectra are not sensitive to modest changes in the vertical integration domain for the Antilles Current transport (not shown).

Seasonal variability in the Antilles Current transport record might be expected at a semiannual time scale based on the spectral peak at 180 days shown here (Figure 10); however, a seasonal climatology of the daily transports shows only a weak indication of semiannual variability (Figure 11). This seasonal record was determined by creating a daily climatology that was then duplicated to produce three identical annual climatologies back-to-back, and this 3-year climatology was then smoothed with a second-order Butterworth low-pass filter (passed both forward and backward) with a 90-day cutoff period. The central year was then extracted, thus eliminating edge transient effects at the beginning and end of the year, and was used as the final daily seasonal climatology. Statistical errors for the seasonal climatology were estimated by calculating the root-mean-squared difference between the 90-day low-pass filtered daily transport time series and the seasonal climatology values for the corresponding day (denoted in top left in Figure 11). There are no obvious month-to-month variations in the amount of scatter around the seasonal climatology (not 


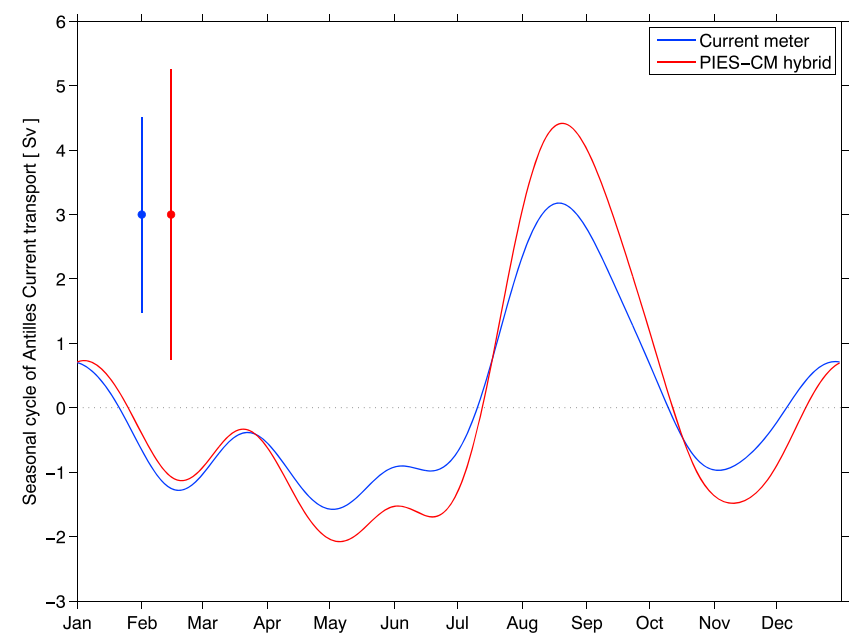

Figure 11. Seasonal cycle of the Antilles Current transport (integrated from the coast out to site B and above 1,000 dbar or the bottom where shallower). Seasonal cycle determined as a daily climatology, smoothed with a 90-day second-order Butterworth filter passed both forward and backward to avoid phase shifting. Seasonal cycle shown for both the direct current meter time series (blue) and the geostrophic hybrid time series (red). One sigma (67\% confidence limit) error bars for each seasonal cycle are shown in the upper left. PIES = pressure-equipped inverted echo sounder; $\mathrm{CM}=$ current meter shown), so only an overall statistical error bar applicable to the entire year is presented. The statistical error bars are quite large compared to the daily climatology differences, and only the transition between the anomalously low values in May-June are significantly different from the anomalously high values in August-September at even the 67\% confidence level indicated by the error bars in Figure 11. Interestingly, the earlier current meter arrays that were in place at essentially these same locations in the late 1980s and early 1990s found a semiannual signal in the Antilles Current transport that had a peak anomalous northward transport in June with a secondary maximum northward flow in December, with roughly equal amplitude maximum southward anomalies in April and October (Lee et al., 1996). The seasonal cycle found herein, based on roughly twice as long a record as was available to Lee et al. (1996), bears essentially no resemblance to the seasonal cycle found by Lee et al. (1996). The amplitude of the seasonal anomalies found by Lee et al. (1996) are also roughly twice as large as those found herein. There were no statistical error bars presented in that Lee et al. (1996) study; however, given that their results were determined from a record half the length of the modern record, it seems likely the error bars on their seasonal estimates must have been even larger than those of the modern time series.

Previous work in the Florida Current just to the west has found that annual variability represents only $~ 9 \%$ of the total variance in the daily Florida Current transports, and there is little indication of semiannual energy in the Florida Current transport record with the largest portion of the observed variance being subsemiannual (Meinen et al., 2010). To determine the breakdown of energy for the Antilles Current, the time series was low-pass, band-pass, and/or high-pass filtered (second-order Butterworth, passed both forward and backward) within the following bounds: periods shorter than 170 days (subsemiannual), periods between 170 and 190 days (semiannual), periods between 190 and 355 days (midrange); periods between 355 and 375 days (annual); and periods longer than 375 days (supra-annual). The results indicate that the percentages of the total variance in the transport record at the time scales listed above are subsemiannual $41 \%$, semiannual $17 \%$, midrange $23 \%$, annual $12 \%$, and supra-annual $8 \%$. Therefore, the Antilles and Florida Currents each exhibit roughly $10 \%$ of their total variance at annual time scales, but the Antilles Current has a larger percentage of its total variance at the semiannual time scale. And for both currents, the dominant time scales of variability are at fairly short (subsemiannual) periods, illustrating the importance of continuous observations in order to properly quantify the transport variations.

\section{Conclusions}

An unprecedentedly rich data set involving velocity observations from five different measurement systems making observations over 10.5 years during 2005-2015 has been used to quantify the structure and variability of the Antilles Current at $26.5^{\circ} \mathrm{N}$. Three of the velocity measurement systems were based on direct measurement technologies: current meters, SADCP, and LADCP. The other two measurement systems provided property measurements directly (CTD) or indirectly via acoustics (PIES) and estimated velocities and transports via geostrophy. The direct velocity measurement systems all agree quite well with one another, as do the two geostrophy-based systems; the direct measurement systems produce weaker, and less variable, estimates of the Antilles Current transports than the geostrophy-based systems. Traditionally, such a disparity might be written off as being the result of the direct measurement systems (e.g., current meters) having insufficient horizontal resolution to properly capture the flow. The SADCP observations, however, can be horizontally integrated across the Antilles Current with far superior horizontal resolution than is available with either the current meters or the LADCP profiles, and yet the SADCP average transport-per-unit-depth structure is nearly identical to that produced by the current meters and/or the LADCP from the surface down to the maximum depth for the SADCP data (Figure 7). Alternately, one might write off such a disparity as resulting from inadequacies in the GEM analysis technique applied to the PIES data. However, there is 
excellent agreement between the PIES data and the CTD measurements. This implies that the disparity between direct and geostrophic methods might be suggesting that the Antilles Current flow is not well characterized by the geostrophic balance inshore of site $\mathrm{A} 2\left(76.75^{\circ} \mathrm{W}\right)$, although this will require future analysis for confirmation.

The record-length-mean geostrophic estimate for the Antilles Current is $4.7 \mathrm{~Sv}$, and the temporal standard deviation of the daily transport estimates is $7.5 \mathrm{~Sv}$. Daily transports observed range between a maximum southward flow of 23.7 Sv and a maximum northward flow of 28.6 Sv. There is some suggestion of seasonal variability in the Antilles Current transports, with a maximum northward transport in August-September; however, the seasonal component of the variability is quite weak, and the statistical error bars on the seasonal estimates are quite large even with 10.5 years of data. There are peaks in the variance-preserving spectrum of the transport at roughly 70 and 180 days, although the latter peak has very large estimated error limits. Lagged correlations between the temperatures and salinities at the 400-dbar core depth of the Antilles Current indicate signs of westward propagation across the array at a speed of roughly $9 \mathrm{~cm} / \mathrm{s}$, likely being the Rossby Wave-like features that have been observed propagating at nearly this same speed at this latitude in past observations (e.g., DiNezio et al., 2009; Domingues et al., 2019; Lee et al., 1996; Meinen \& Garzoli, 2014). Although some correlation between the $26.5^{\circ} \mathrm{N}$ Antilles Current and $27^{\circ} \mathrm{N}$ Florida Current volume transport observations have been found in the past using shorter segments of data (FrajkaWilliams et al., 2013), with this 10.5-year record, there is no significant correlation between the transports of the two currents. This is true for in-phase variations as well as for lags/leads of up to 5 years, which is consistent with a recent model-based analysis that indicates that transmission of information from westward propagating Rossby Wave-like features through the Bahamas Island chain will be complex with varying phases reflecting the varying coastal wave and/or wall jet time scales (Domingues et al., 2019). The 10.5 years of overlapping data from these observing systems demonstrates the many advantages of using complementary observations in analyzing the structure and variability of important boundary currents such as the Antilles Current and provides strong motivation for such concurrent measurements continuing into the future.

\section{Appendix A: Using Moored T and S Data to Fill Data Gaps in the PIES Records}

As with any long-term observing endeavor, instrument failure is a somewhat inevitable problem over the course of the study. The PIES array was designated as the "backbone" of the calculations herein for two reasons: (1) because of the higher horizontal resolution of the PIES array, specifically the existence of site C which allows for evaluation of the counter-flow just offshore of the Antilles Current; and (2) the natural integration of the geostrophic calculations inherent in the PIES method over the point measurement nature (horizontally) of the current meters. As a result, the data from the moored MicroCATs and the BPR were used to fill the gaps in the PIES records in order to obtain travel time and bottom pressure records at each site as best as possible.

The gridded temperature and salinity profiles from the MicroCAT sensors on the tall moorings were used to simulate travel time measurements at 1,000 dbar using the sound speed equation of Del Grosso (1974). Comparisons of PIES-measured and tall mooring-simulated travel times when both observations were available from instruments at the same site are quite good, with correlation coefficients meeting or exceeding $r=$ 0.8 and root-mean-squared differences of $1.3 \mathrm{~ms}$ or less (Table A1). This is to be expected given the excellent agreement between the PIES-GEM estimates of temperature and salinity and the gridded, mooring-motion corrected, temperature and salinity from the tall moorings. As an example, Figure A1 presents the temperature (top panel) and salinity (bottom panel) at $400 \mathrm{dbar}$ from both the PIES-GEM estimates from site B (red lines) and from the gridded tall mooring data from mooring WB-3 (blue lines). The crosshatching indicates a period when the PIES at this site failed, and the travel time record was "filled" as discussed above. Three conclusions are evident from this comparison. First, overall, the agreement between the two systems is quite good, with the major events in both temperature and salinity being captured by both systems. Second, the data are thus quite complementary when one or the other systems suffers a failure. Third, the PIES-GEM data can also help identify problems in the tall mooring data. As two examples of the latter point, notice both the large vertical spikes in the tall mooring data in late 2009 and the abrupt shift to lower salinities in 20142015. The large vertical spikes in the tall mooring data (blue spikes in late 2009) are easily identifiable, and even the simulated travel time would have provided a more realistic time series; these spikes were the result 
Table A1

Statistical Comparison of Tall Mooring and PIES Observations at Each of the Sites

\begin{tabular}{|c|c|c|c|c|c|}
\hline Mean difference & & Std. dev. difference & RMS difference & Correlation coefficient $r$ & Days of overlap \\
\hline \multicolumn{6}{|l|}{ Travel time (ms) } \\
\hline Site A \& WB-1 & 0.24 & 0.49 & 0.54 & 0.80 & 3,304 \\
\hline Site A2 \& WB-2 & 0.59 & 0.64 & 0.87 & 0.83 & 1,457 \\
\hline Site B \& WB-3 & 0.52 & 0.95 & 1.1 & 0.84 & 3,068 \\
\hline Site D \& WB-4 & 0.43 & 1.2 & 1.3 & 0.85 & 787 \\
\hline Site E \& WB-5 & 0.74 & 1.3 & 1.3 & 0.88 & 1,188 \\
\hline \multicolumn{6}{|l|}{ Pressure (dbar) } \\
\hline Site A \& WB-1 & $\mathrm{N} / \mathrm{A}$ & N/A & $\mathrm{N} / \mathrm{A}$ & $\mathrm{N} / \mathrm{A}$ & N/A \\
\hline Site A2 \& WB-2 & -0.0006 & 0.013 & 0.013 & 0.81 & 1,455 \\
\hline Site B \& WB-3 & 0.0003 & 0.025 & 0.025 & 0.59 & 492 \\
\hline Site D \& WB-4 & -0.0013 & 0.025 & 0.025 & 0.83 & 3,546 \\
\hline Site E \& WB-5 & -0.0019 & 0.012 & 0.012 & 0.93 & 831 \\
\hline
\end{tabular}

Note. Travel times simulated from moored T, S, and P sensors on tall moorings are compared to the pressure-equipped inverted echo sounders (PIES) travel time measurements from nearby moorings, and bottom pressure measurements from Bottom Pressure Recorder located near the base of the tall moorings are compared to concurrent bottom pressure measurements from the PIES. Note that gaps in the PIES site $\mathrm{C}$ travel time and pressure were filled utilizing the data from the WB-4 mooring and the associated Bottom Pressure Recorder by means of linear relationships determined between the PIES data at sites C and D when both were in place (2,822 days of overlap for travel time and 2,873 days for bottom pressure). The correlation coefficient between the travel times at the two PIES sites was $r=0.82$; for bottom pressure, it was $r=0.74$. RMS $=$ root-mean-squared.

of the top portion of the mooring breaking off, and as a result, the gridded profiles were filled upward via extrapolation from the deeper sensors, which is of course not as accurate as interpolating between real measurements. The abrupt salinity shift in 2014-2015 resulted from a calibration mistake in one of the MicroCAT sensors, highlighting how the complementary data sets can aid each other.
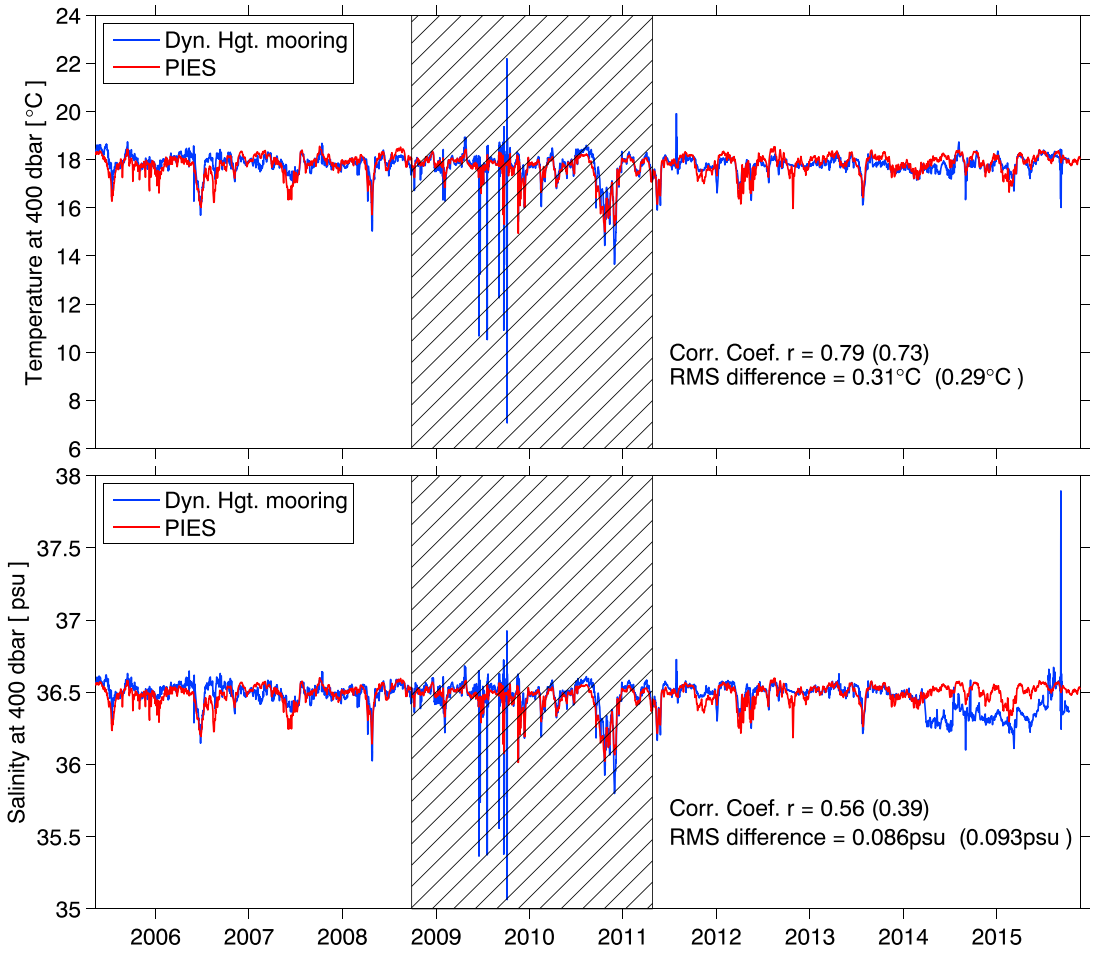

Figure A1. Comparison of the PIES-Gravest Empirical Mode temperature (top) and salinity (bottom) at 400 dbar at site B to the concurrent temperature and salinity at $400 \mathrm{dbar}$ from the gridded tall mooring data at that site. Crosshatched portion of the time series indicates the period when the moored temperature and salinity data within the upper 1,000 dbar has been used to fill a gap in the PIES record as discussed in the text. Correlation coefficients between the time series and the RMS differences are noted on each panel. Values in parentheses were calculated after excluding the crosshatched portion of the record. PIES = pressure-equipped inverted echo sounder; RMS = root-mean-squared. 


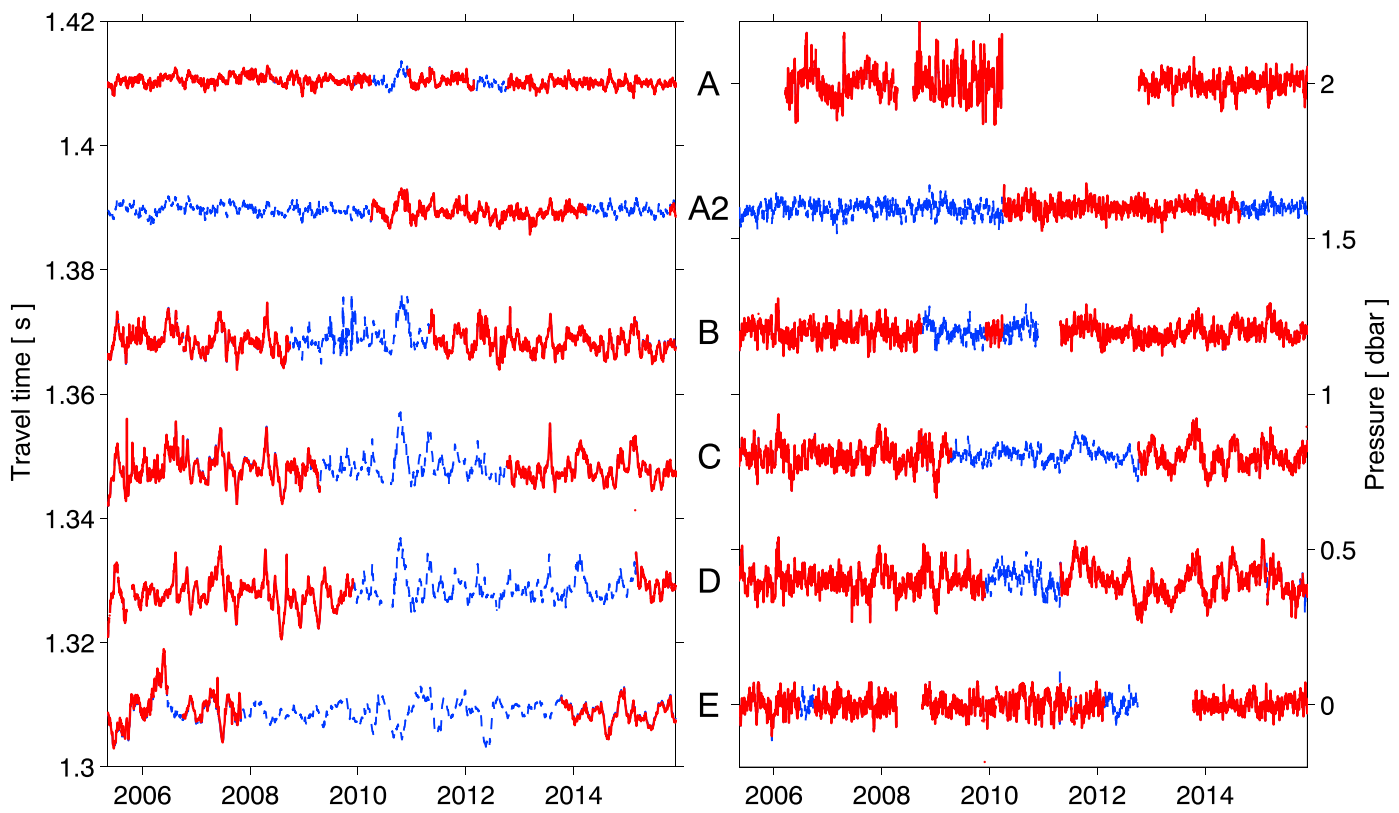

Figure A2. Illustration of gap filling in the pressure-equipped inverted echo sounder records using moored temperature, salinity, and Bottom Pressure Recorder observations. The actual pressure-equipped inverted echo sounder data are shown in thick red for the acoustic travel time (left) and the bottom pressure (right). Estimated values of travel time from the moored temperature and salinity data are shown as blue lines (left); bottom pressure data from the Bottom Pressure Recorder moorings are shown as blue lines (right). Site labels are shown between the two panels; see Table 1 for the locations of the instruments. Travel time and pressure data have been offset by $20 \mathrm{~ms}$ or $0.4 \mathrm{dbar}$, respectively, to avoid overplotting the individual records.

The BPR records of bottom pressure can be used to fill gaps in the PIES bottom pressure records in a very straightforward manner once the sensor drifts have been removed via the standard methods (e.g., Watts \& Kontoyiannis, 1990; Donohue et al., 2010). The correlations between the BPR and PIES pressure records when both are available are similarly high, with $r>0.8$ for all but one relatively short overlap site (Table A1). The root-mean-squared differences from the overlapping records are all $0.025 \mathrm{dbar}$ or less.

For one location, site $\mathrm{C}$, there was no spatially coincident tall mooring with MicroCAT sensors or a BPR during the majority of this time period. Gaps in travel time and bottom pressure at site $\mathrm{C}$ were filled by utilizing a linear relationship between the PIES data at sites $\mathrm{C}$ and $\mathrm{D}$ when both were in place (Table A1). Once all of the gaps were filled as best as possible at all sites, the travel time records were essentially continuous, and the bottom pressure records were continuous except for the bottom pressure at site A, which is not used in this study, and some short gaps at sites B and E (Figure A2).

\section{Appendix B: Accuracy of the Estimated Antilles Current Transports}

Estimating the accuracy of the calculated Antilles Current transports can be approached in either a first principle manner or in a "comparison to an alternative measure" manner. Using a first principle-based method, Meinen et al. (2004) derived an estimated accuracy for the daily baroclinic Antilles Current transport estimates from PIES-GEM (relative to an assumed level of no motion) of $2.0 \mathrm{~Sv}$, with an estimated bias accuracy for the time mean of $1.7 \mathrm{~Sv}$. These accuracy estimates include errors in the measured travel times, the calibration of the measured travel times into travel times at 1,000 dbar, and errors based on the scatter between the original hydrographic data and the smoothed GEM fields. Those earlier values are reasonable estimates for the more recent PIES-GEM data presented herein as well. The Meinen et al. (2004) estimates did not include transport errors inshore of site A nor did they include transport errors associated with a reference velocity (needed to get absolute transports). For the purposes of the PIES-hybrid absolute Antilles Current transport presented herein, therefore, those two sources of error must be added. As both are determined from the current meter and ADCP data, which is independent of the travel time and GEM look-up table data, these sources of error can be combined in a square root of the sum of squares manner. 
Acknowledgments

The authors would like to express their appreciation to the ship captains and crews of the R/Vs Endeavor, Seward Johnson, Cape Hatteras, Knorr,

Oceanus, and Atlantic Explorer, as well as the NOAA Ship Ronald H. Brown and the NERC Ships RRS Discovery (1962), RRS James Cook, and RRS Discovery (2013) for their outstanding support of the observational field program. The PIES array, and the collection of CTD$\mathrm{O}_{2}$, LADCP, and SADCP data along the array, has been supported by the U.S. NOAA Climate Program OfficeOcean Observing and Monitoring Division via the Western Boundary Time Series (WBTS) project (FundRef 100007298) and by the U.S. NOAA Atlantic Oceanographic and Meteorological Laboratory. The tall moorings (current meter, MicroCAT, and moored $\mathrm{ADCP}$ ) and the BPR are/have been jointly funded by the U.K. Natural Environment Research Council via the RAPID, RAPIDWATCH, and RAPID AMOC programmes and the U.S. National Science Foundation via the Meridional Overturning Circulation Heat-flux Array project (grants 0728108 and 1332978). C. M., R. S., R. G., E. J., and S G. received some support from the WBTS project and/or from the NOAA Atlantic Oceanographic and Meteorological Laboratory for this work. R. G. and S. G. also were supported in part under the auspices of the Cooperative Institute for Marine and Atmospheric Studies (CIMAS), a cooperative institute of the University of Miami and NOAA, cooperative agreement NA10OAR4320143. Renellys Perez, Marion Kersalé, David Smeed, Denis Volkov, Josep Pelegrí, and an anonymous reviewer provided several suggestions that were helpful for this analysis and/or for preparing this manuscript.
The reference velocity error and the error in the gridded transports inshore of site A were estimated following the methods presented in W. E. Johns et al. (2005), taking into account the accuracy of the measured velocities, potential errors associated with the vertical gridding (and mooring motion) to produce vertical profiles of velocity, and the horizontal interpolation between moorings to produce averages between pairs of moorings. The velocity accuracies were multiplied by the appropriate areas to yield the corresponding transport accuracies. These methods yield a daily transport random error contribution for the current meter reference velocity data of $0.5 \mathrm{~Sv}$ for the flow between sites A and B and a bias error estimate of $0.3 \mathrm{~Sv}$. Inshore of site A, the estimated accuracies from the current meter data are a random error of $0.1 \mathrm{~Sv}$ and a bias error of $0.1 \mathrm{~Sv}$. Combining these error components with the geostrophy-based estimates from Meinen et al. (2004) as the square root of the sum of the squares yields an overall random error bar for the absolute PIES-hybrid daily Antilles Current transports of $2.1 \mathrm{~Sv}$ and an overall bias error bar of $1.7 \mathrm{~Sv}$.

For comparison to the random accuracy estimate, the standard deviation of the differences between the current meter-based Antilles Current transport estimate and the PIES-hybrid estimate (i.e., the red and blue lines in Figure 9) is 3.9 Sv. For comparison to the bias accuracy estimate, the mean difference between the two time series is 1.9 Sv. The transport time series contain roughly 85 degrees of freedom (e.g., Emery \& Thomson, 1997), so the error in the estimated mean value would be the square root of the sum of the squares of the bias error $(1.7 \mathrm{~Sv})$ plus the random error $(2.1 \mathrm{~Sv})$ where the latter is reduced by the square root of the number of degrees of freedom (85). The random term becomes negligibly small compared to the bias error estimate, and so the resulting mean transport accuracy estimate for the Antilles Current is $1.7 \mathrm{~Sv}$. Using the first principle error estimates, the Antilles Current transport is accurate to within 2.1 Sv on a daily basis, and the record-length mean is accurate to within $1.7 \mathrm{~Sv}$. More conservatively, one could assume the current meter observations are "perfect," and then random accuracy estimate for the PIES-hybrid transports would be $3.9 \mathrm{~Sv}$ for the daily data, while the bias accuracy would be $1.9 \mathrm{~Sv}$. The actual accuracy for these transports is likely somewhere between these two extremes.

\section{Data Availability}

The PIES, CTD-O ${ }_{2}$, LADCP, and SADCP data presented herein were funded primarily by the U.S. National Oceanic and Atmospheric Administration, with additional support for ship-time from the U.S. National Science Foundation and the U.K. Natural Environment Research Council. These data are freely available on the Western Boundary Time Series project webpage (www.aoml.noaa.gov/phod/wbts/). The BPR and tall mooring data (current meter, MicroCAT, and moored ADCP) presented herein were funded by the U.K. Natural Environment Research Council and the U.S. National Science Foundation, with additional support for ship-time from the U.S. National Oceanic and Atmospheric Administration. The individual BPR, current meter, MicroCAT, and moored ADCP data are available on the BODC web page (www.bodc.ac.uk/rapid$\mathrm{moc} /$ ). The gridded tall mooring data are freely available from the RAPID-MOC web page (www.rapid.ac. uk/rapidmoc). The Argo data used for building the GEM fields discussed herein were collected and made freely available by the Coriolis project and programs that contribute to it (www.coriolis.eu.org).

\section{References}

Bryden, H. L., Johns, W. E., \& Saunders, P. M. (2005). Deep Western Boundary Current east of Abaco: Mean structure and transport. Journal of Marine Research, 63(1), 35-57. https://doi.org/10.1357/0022240053693806

Chelton, D. B., \& Schlax, M. G. (1996). Global observations of oceanic Rossby Waves. Science, 272(5259), 234-238. https://doi.org/10.1126/ science.272.5259.234

Costin, J. M. (1968). Direct current measurements in the Antilles Current. Journal of Geophysical Research, 73, 3341-3344. https://doi.org/ 10.1029/JB073i010p03341

Cunningham, S. A., Kanzow, T., Rayner, D., Baringer, M. O., Johns, W. E., Marotzke, J., et al. (2007). Temporal variability of the Atlantic Meridional Overturning Circulation at $26.5^{\circ}$ N. Science, 317, 935-938. https://doi.org/10.1126/science.1141304

Del Grosso, V. A. (1974). New equation for the speed of sound in natural waters (with comparisons to other equations). The Journal of the Acoustical Society of America, 56(4), 1084-1091. https://doi.org/10.1121/1.1903388

DiNezio, P. N., Gramer, L. J., Johns, W. E., Meinen, C. S., \& Baringer, M. O. (2009). Observed Interannual variability of the Florida Current: Wind forcing and the North Atlantic Oscillation. Journal of Physical Oceanography, 39(3), 721-736. https://doi.org/10.1175/ 2008JPO4001.1

Domingues, R., Baringer, M., \& Goni, G. (2016). Remote sources for year-to-year changes in the seasonality of the Florida Current transport. Journal of Geophysical Research: Oceans, 121, 7547-7559. https://doi.org/10.1002/2016JC012070

Domingues, R. M., Johns, W. E., \& Meinen, C. S. (2019). Mechanisms of eddy-driven seasonal variability of the Florida Current. Journal of Physical Oceanography, 5, 1319-1338. https://doi.org/10.1175/JPO-D-18-0192.1 
Donohue, K. D., Watts, D. R., Tracey, K. L., Greene, A. D., \& Kennelly, M. (2010). Mapping circulation in the Kuroshio Extension with an array of current and pressure recording inverted echo sounders. Journal of Atmospheric and Oceanic Technology, 27(3), 507-527. https:// doi.org/10.1175/2009JTECHO686.1

Duncan, C. P., Schladow, S. G., \& Williams, W. G. (1982). Surface currents near the Greater and Lesser Antilles. International Hydrographic Review, 59(2), 67-78.

Emery, W. J., \& Meincke, J. (1986). Global water masses: Summary and review. Oceanologica Acta, 9(4), 383-391.

Emery, W. J., \& Thomson, R. E. (1997). Data analysis methods in physical oceanography (p. 638). Pergamon, Oxford, UK: Elsevier.

Findlay, A. G., \& Maury, M. F. (1853). Oceanic currents, and their connection with the proposed Central-America Canals. Journal of the Royal Geographical Society of London, 23, 217-242. https://doi.org/10.2307/1797966

Fine, R. A., \& Molinari, R. L. (1988). A continuous Deep Western Boundary Current between Abaco (26.5 $\mathrm{N})$ and Barbados $\left(13^{\circ} \mathrm{N}\right)$. Deep Sea Research Part A: Oceanographic Research Papers, 35(9), 1441-1450. https://doi.org/10.1016/0198-0149(88)90096-9

Frajka-Williams, E., Johns, W. E., Meinen, C. S., Beal, L. M., \& Cunningham, S. A. (2013). Eddy impacts on the Florida Current. Geophysical Research Letters, 40, 349-353. https://doi.org/10.1002/grl.50115

Frajka-Williams, E., Meinen, C. S., Johns, W. E., Smeed, D. A., Duchez, A., Lawrence, A. J., et al. (2016). Compensation between meridional flow components of the AMOC at $26^{\circ}$ N. Ocean Science, 12(2), 481-493. https://doi.org/10.5194/os-12-481-2016

Gill, A. E. (1982). Atmosphere-ocean dynamics, (p. 662). San Diego, USA: Academic Press.

Gunn, J. T., \& Watts, D. R. (1982). On the currents and water masses north of the Antilles/Bahamas arc. Journal of Marine Research, 40(1), $1-18$.

Hacker, P., Firing, E., Wilson, W. D., \& Molinari, R. (1996). Direct observations of the current structure east of the Bahamas. Geophysical Research Letters, 23, 1127-1130. https://doi.org/10.1029/96GL01031

Hooper, J. A., \& Baringer, M. O. (2016) Hydrographic measurements collected aboard the UNOLS Ship R/V Endeavor. October 3-20, 2015: Western boundary time series cruise EN570 (AB1510). NOAA Data Report, OAR-AOML-54, 188 pp., doi: https://doi.org/10.7289/V5/DRAOML-54.

Johns, E., Fine, R. A., \& Molinari, R. L. (1997). Deep flow along the western boundary south of the Blake Bahama Outer Ridge. Journal of Physical Oceanography, 27(10), 2187-2208. https://doi.org/10.1175/1520-0485(1997)027<2187:DFATWB>2.0.CO;2

Johns, W. E., Beal, L. M., Baringer, M. O., Molina, J. R., Cunningham, S. A., Kanzow, T., \& Rayner, D. (2008). Variability of Shallow and Deep Western Boundary Currents off the Bahamas during 2004-2005: Results from the $26^{\circ} \mathrm{N}$ RAPID-MOC Array. Journal of Physical Oceanography, 38(3), 605-623. https://doi.org/10.1175/2007JPO3791.1

Johns, W. E., Kanzow, T., \& Zantopp, R. (2005). Estimating ocean transports with dynamic height moorings: An application in the Atlantic Deep Western Boundary Current at $26^{\circ}$ N. Deep Sea Research, Part I, 52(8), 1542-1567. https://doi.org/10.1016/j.dsr.2005.02.002

Kanzow, T., Cunningham, S. A., Rayner, D., Hirshi, J. J.-M., Johns, W. E., Baringer, M. O., et al. (2007). Observed flow compensation associated with the Meridional Overturning at $26.5^{\circ} \mathrm{N}$ in the Atlantic. Science, 317(5840), 938-941. https://doi.org/10.1126/ science.1141293

Leaman, K. D., \& Harris, J. E. (1990). On the average absolute transport of the Deep Western Boundary Currents east of Abaco Island, the Bahamas. Journal of Physical Oceanography, 20(3), 467-475. https://doi.org/10.1175/1520-0485(1990)020<0467:OTAATO>2.0. $\mathrm{CO} ; 2$

Lee, T. N., Johns, W., Schott, F., \& Zantopp, R. (1990). Western boundary current structure and variability east of Abaco, Bahamas at $26.5^{\circ}$ N. Journal of Physical Oceanography, 20(3), 446-466. https://doi.org/10.1175/1520-0485(1990)020<0446:WBCSAV >2.0.CO;2

Lee, T. N., Johns, W. E., Zantopp, R. J., \& Fillenbaum, E. R. (1996). Moored observations of western boundary current variability and thermohaline circulation at $26.5^{\circ} \mathrm{N}$ in the subtropical North Atlantic. Journal of Physical Oceanography, 26(6), 962-983. https://doi.org/ 10.1175/1520-0485(1996)026<0962:MOOWBC >2.0.CO;2

Maloney, W. E. (1968). A study of the Antilles Current using moored current meter arrays. U.S. Naval Oceanographic Office, Tech. Rept. 199, 142pp. Retrieved from https://babel.hathitrust.org/cgi/pt?id=uc1.31822020640751;view=1up;seq=15

McCarthy, G. D., Smeed, D. A., Johns, W. E., Frajka-Williams, E., Moat, B. I., Rayner, D., et al. (2015). Measuring the Atlantic Meridional Overturning Circulation at $26^{\circ}$ N. Progress in Oceanography, 130, 91-111. https://doi.org/10.1016/j.pocean.2014.10.006

Meinen, C. S., Baringer, M. O., \& Garcia, R. F. (2010). Florida Current transport variability: An analysis of annual and longer-period signals. Deep Sea Research, Part I, 57(7), 835-846. https://doi.org/10.1016/j.dsr.2010.04.001

Meinen, C. S., Baringer, M. O., \& Garzoli, S. L. (2006). Variability in Deep Western Boundary Current transports: Preliminary results from $26.5^{\circ} \mathrm{N}$ in the Atlantic. Geophysical Research Letters, 33, L17610. https://doi.org/10.1029/2006GL026965

Meinen, C. S., \& Garzoli, S. L. (2014). Attribution of Deep Western Boundary Current variability at $26.5^{\circ}$ N. Deep Sea Research, Part I, 90 , 81-90. https://doi.org/10.1016/j.dsr.2014.04.016

Meinen, C. S., Garzoli, S. L., Johns, W. E., \& Baringer, M. O. (2004). Transport variability of the Deep Western Boundary Current and the Antilles Current off Abaco Island, Bahamas. Deep-Sea Research Part I, 51(11), 1397-1415. https://doi.org/10.1016/j.dsr.2004.07.007

Meinen, C. S., Johns, W. E., Garzoli, S. L., Van Sebille, E., Rayner, D., Kanzow, T., \& Baringer, M. O. (2013). Variability of the Deep Western Boundary Current at $26.5^{\circ} \mathrm{N}$ during 2004-2009. Deep-Sea Research Part II, 85, 154-168. https://doi.org/10.1016/j.dsr2.2012.07.036

Meinen, C. S., \& Luther, D. S. (2016). Structure, transport, and vertical coherence of the Gulf Stream from the Straits of Florida to the Southeast Newfoundland Ridge. Deep Sea Research, Part I, 112, 137-154. https://doi.org/10.1016/j.dsr.2016.03.002

Meinen, C. S., \& Watts, D. R. (1997). Further evidence that the sound speed algorithm of Del Grosso is more accurate than that of Chen and Millero. The Journal of the Acoustical Society of America, 102(4), 2058-2062. https://doi.org/10.1121/1.419655

Meinen, C. S., \& Watts, D. R. (1998). Calibrating inverted echo sounders equipped with pressure sensors. Journal of Atmospheric and Oceanic Technology, 15(6), 1339-1345. https://doi.org/10.1175/1520-0426(1998)015<1339:CIESEW >2.0.CO;2

Meinen, C. S., \& Watts, D. R. (2000). Vertical structure and transport on a transect across the North Atlantic Current near $42^{\circ} \mathrm{N}$ : Time series and mean. Journal of Geophysical Research, 105, 21,869-21,891. https://doi.org/10.1029/2000JC900097

Molinari, R. L., Fine, R. A., \& Johns, E. (1992). The Deep Western Boundary Current in the tropical North Atlantic Ocean. Deep Sea Research Part A: Oceanographic Research Papers, 39(11-12), 1967-1984. https://doi.org/10.1016/0198-0149(92)90008-H

Molinari, R. L., Fine, R. A., Wilson, W. D., Curry, R. G., Abell, J., \& McCartney, M. S. (1998). The arrival of recently formed Labrador Sea Water in the Deep Western Boundary Current at $26.5^{\circ}$ N. Geophysical Research Letters, 25(13), 2249-2252. https://doi.org/10.1029/ 98GL01853

Munk, W., \& Cartwright, D. (1966). Tidal spectroscopy and prediction. Philosophical Transactions. Royal Society of London, 259(1105), 533-581. https://doi.org/10.1098/rsta.1966.0024

Osychny, V., \& Cornillon, P. (2004). Properties of Rossby Waves in the North Atlantic estimated from satellite data. Journal of Physical Oceanography, 34(1), 61-76. https://doi.org/10.1175/1520-0485(2004)034<0061:PORWIT>2.0.CO;2 
Pillsbury, J. E. (1889). Gulf Stream explorations-Observations of currents-1888 and 1889. Report of the Superintendent of the U.S. Coast and Geodetic Survey, Appendix, 16, 467-477.

Pillsbury, J. E. (1890). The Gulf Stream-A description of the methods employed in the investigation, and the results of the research. Report of the Superintendent of the U.S. Coast and Geodetic Survey, Appendix, 10, 461-620.

Rayner, D., Hirschi, J. J.-M., Kanzow, T., Johns, W. E., Cunningham, S. A., Wright, P. G., et al. (2011). Monitoring the Atlantic Meridional Overturning Circulation. Deep Sea Research, Part I, 58(17-18), 1744-1753. https://doi.org/10.1016/j.dsr2.2010.10.056

Rosenfeld, L. K., Molinari, R. L., \& Leaman, K. D. (1989). Observed and modeled annual cycle of transport in the Straits of Florida and east of Abaco Island, the Bahamas (26.5 $\left.{ }^{\circ} \mathrm{N}\right)$. Journal of Geophysical Research, 94, 4867-4878. https://doi.org/10.1029/JC094iC04p04867

Schmitz, W. J., \& McCartney, M. S. (1993). On the North Atlantic circulation. Reviews of Geophysics, 31(1), 29-49. https://doi.org/10.1029/ 92RG02583

Schmitz, W. J. Jr., \& Richardson, P. L. (1991). On the sources of the Florida Current. Deep Sea Research, 38(Supplement 1, S379-S409. https://doi.org/10.1016/S0198-0149(12)80018-5

Smeed, D. A., Josey, S. A., Beaulieu, C., Johns, W. E., Moat, B. I., Frajka-Williams, E., et al. (2018). The North Atlantic Ocean is in a state of reduced overturning. Geophysical Research Letters, 45, 1527-1533. https://doi.org/10.1002/GL076350

Smith, W. H. F., \& Sandwell, D. T. (1997). Global sea floor topography from satellite altimetry and ship depth soundings. Science, 277(5334), 1956-11962.

Tomczak, M., \& Godfrey, J. S. (1994). Regional oceanography: An introduction (p. 422). Pergamon: Elsevier Science Inc.

van Sebille, E., Baringer, M. O., Johns, W. E., Meinen, C. S., Beal, L. M., de Jong, M. F., \& van Aken, H. M. (2011). Propagation pathways of Classical Labrador Sea Water from its source region to $26^{\circ}$ N. Journal of Geophysical Research, 116, C12027. https://doi.org/10.1029/ 2011JC007171

Visbeck, M. (2002). Deep velocity profiling using lowered acoustic Doppler current profilers: Bottom track and inverse solutions. Journal of Atmospheric and Oceanic Technology, 19, 794-807. https://doi.org/10.1175/1520-0426(2002)019<0794:DVPULA>2.0.CO;2

Watts, D. R., \& Kontoyiannis, H. (1990). Deep-ocean bottom pressure measurement: Drift removal and performance. Journal of Atmospheric and Oceanic Technology, 7(2), 296-306. https://doi.org/10.1175/1520-0426(1990)007<0296:DOBPMD>2.0.CO;2

Worthington, L. V. (1959). The $18^{\circ}$ water in the Sargasso Sea. Deep Sea Research, 5(2-4), 297-305.

Worthington, L. V. (1976). On the North Atlantic Circulation (Vol. 6, p. 110). Baltimore, Maryland: Johns Hopkins University Oceanographic Studies.

Wüst, G. (1924). Florida und Antillenstrom, eine hydrodynamische Untersuchung. Veröffentlichungen des Instituts für Meereskunde Reihe A, 12,48 